\title{
Recent Research Advances in Plasma Spraying of Bulk-Like Dense Metal Coatings with Metallurgically Bonded Lamellae
}

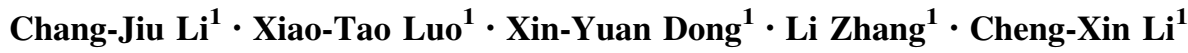

Submitted: 6 August 2021 / in revised form: 8 November 2021/Accepted: 6 December 2021/Published online: 28 January 2022 (C) ASM International 2022

\begin{abstract}
Although thermal spray metallic coatings have been widely used for materials protection from wear, corrosion and oxidation, its porous feature limits the full utilization of materials potential. Moreover, the oxidation inherent to thermal spraying in the ambient atmosphere is detrimental to interlamellar bonding formation, which further degrades the performance of thermal spray metal coatings. How to tape out the full potential of spray materials in the form of the coating is a still great challenge to thermal spray coating technology. Facing such challenge, recent efforts have been made to deposit dense metallic coatings with sufficiently bonded lamellae by oxide-free molten droplets through atmospheric plasma spraying. In this paper, the strategies for depositing bulklike metal coatings will be reviewed. The formation of the bulk-like coating through post-spray treatments is briefly reviewed including post-spray heat treatment and laser remelting following the brief introduction to the features of thermal spray metallic coatings. The effect of the substrate preheating temperature on the splat formation and subsequently the adhesion formation was examined to reveal the dominant limitation of resultant oxide scale. Then, the role of the deposition temperature on the formation of bulk-like
\end{abstract}

This article is an invited paper selected from presentations at the 2021 International Thermal Spray Conference, ITSC2021 that was held virtually May 25-28, 2021 due to travel restrictions related to the coronavirus (COVID-19) pandemic. It has been expanded from the original presentation.

Chang-Jiu Li

licj@mail.xjtu.edu.cn

1 State Key Laboratory for Mechanical Behavior of Materials, School of Materials Science and Engineering, Xi' an Jiaotong University, Xi'an 710049, Shaanxi Province, People's Republic of China metal deposits with neglecting the effect of oxidation during spraying by vacuum plasma spraying practices is shortly presented. The recent progress on the new strategies to develop spread-fusing bonding mechanism and in-situ in-flight deoxidizing mechanism through developing ultrahot metallic droplets will be introduced. The thermodynamics and kinetics requirements for the in-situ in-flight deoxidizing through deoxidizer elements adding to alloy spray powders for achieving oxide-free molten droplets in the ambient atmosphere are examined. The conditions to develop the spread-fusing mechanism during the spreading of impacting molten metal droplet for metallurgical bonding are presented. It is obvious from this review paper that the realization of two mechanisms depends on both the spray materials design and heating control of in-flight particles. Through the generation of ultra-hot droplets by plasma spraying to achieve oxide-free molten droplets, strategically it will be possible to deposit bulk-like dense metallic coating through spread-fusing of splat surfaces with limited post-spray oxidation. Such strategies will tape out the full potential of coating materials and open up the new application fields for plasma spraying.

Keywords cohesion - in-situ deoxidizing effect - metallic coating - metallurgical bonding - oxide-free metal droplet . plasma spraying $\cdot$ self-bonding $\cdot$ spread-fusing

\section{Introduction}

Thermal spray metal coatings were born with thermal spray technology in the year 1910 (Ref 1). In the following 110 years, different thermal spray processes, including very early flame spraying, arc spraying, plasma spraying, and high-velocity oxy-fuel (HVOF) spraying, have been 
gradually developed to deposit different metal alloy coatings to fulfill all kinds of requirements for various of industrial applications (Ref 2, 3). All these technologies have been developed for effectively heating and accelerating spray particles to generate high velocity and high temperature molten particles stream, which are sprayed onto a substrate for coating deposition. A thermal spray coating is primarily deposited by the successive impact of molten droplets followed by their spreading, rapid cooling and solidification on a rough substrate surface. Therefore, thermally sprayed coatings generally present a lamellar structure packed by multiple flattened splats. The quality of the bonding between coating and substrate, and between the adjacent splats determines the adhesion and cohesion, respectively, and thus is the central concern regarding effective coating applications. Due to insufficient filling of impacting molten droplet into cavities on a rough surface and very limited wetting time of melt to substrate surface less than $10 \mu$ s before the solidification of the melt starts, the coatings in the as-sprayed state are characterized as porous microstructure with a relatively low density. Moreover, the coating presents lower adhesive strength and limited cohesive strength in comparison with the bulk counterpart (Ref 4). Taking mild steel coating as an example, its adhesive strength of $116 \mathrm{~J} / \mathrm{m}^{2}$ is lower than the cohesive strength, and its cohesive fracture toughness of $261 \mathrm{~J} / \mathrm{m}^{2}$ is remarkably lower than $600-60000 \mathrm{~J} / \mathrm{m}^{2}$ for brittle fracture of bulk steel (Ref 4). This is because the adhesive strength is mainly determined by the mechanical interlocking (Ref 5, 6), and usually limited contact is formed between adjacent splats within a coating (Ref 7). However, the coating mechanical properties and transportation properties are positively proportional to the interlamellar bonding ratio (Ref 8 ). Quantitative characterizations revealed that interlamellar bonding ratio is typically less than one-third (Ref 9, 10). Such a low interlamellar bonding ratio sets up a low top celling for thermal spray coating properties compared to their counterpart bulk materials. For example, Young's moduli of different coatings are lower than one-third bulk materials (Ref 11). The abrasive wear resistances of the as-sprayed coatings taking flame-sprayed NiCrBSi coating (Ref 12) and HVOF-sprayed WC-Co coatings (Ref 13) as examples are relatively lower than their corresponding fused bulk and sintered bulk, respectively. Therefore, one biggest challenge born with thermal spraying is how to improve the adhesion and cohesion of the coating, to reduce the porosity, and consequently deposit a bulk-like coating, although in many applications the coatings with a porous microstructure are required such as for applications to abradable coatings (Ref 14), catalytic coatings (Ref 15) and so on.
Another concern adherent to thermal spray metal coatings is how to control the oxidation during spray deposition to reduce oxide inclusions since the resultant oxide inclusions in most cases degrade the coating performance by lowering coating adhesion and cohesion (Ref 16) although they may improve wear performance by increasing coating hardness (Ref 5, 17, 18). Gan and Berndt (Ref 16) presented the oxidation mechanisms, the effect of oxidation on coating properties and oxidation control approaches in their review paper. While the use of a shroud or/and shield is effective to protect metal coating against oxidation, it is still tough to make effective protection for the parts with complex geometry. It is interesting how to utilize the sacrificial elements in alloy powders as deoxidizer elements as reported by Zeng et al. (Ref 19, 20) for protection of in-flight molten droplets from oxidation throughout the whole spray distance range.

Based on thermal spray coating formation theory, to deposit a bulk-like metal coating by reducing coating porosity, the first measure for most spray processes using powder as feedstock is to increase the temperature and velocity of spray particles by optimizing the processing parameters. Effective heating is generally attempted by using high temperature spray processes and increasing the thermal power of heat sources (Ref 1). Since heating of spray particles takes place during in-flight, any effort to enhance the heating ability of the heat source leads to the increase of in-flight particle velocity and subsequently shortening of heating time on the other hand. The above contradictoriness involving in-flight spray particle heating in any flame jet limits the heating up ability of spray particles (Ref 21). Moreover, the vaporization of molten spray particles also limits the maximum particle temperature (Ref 22 ). Thus, the processes are usually optimized to achieve sufficient melting of spray particles. On the other hand, since higher velocity impact results in higher transient contact pressure at the particle-substrate interface and spreading of the molten droplet (Ref 23), it could enhance the filling ability of the spreading melt to surface cavities. It is generally accepted that increasing the particle velocity of droplets is effective to deposit a dense coating ( $\operatorname{Ref} 1,2$ ). Accordingly, high power plasma spraying and HVOF processes have been developed. By optimizing spray conditions, the apparent porosity of a metal coating deposited by HVOF can be reduced to a low level of about or less than $1 \%$ (Ref 24, 25). However, despite the apparent dense microstructure of HVOF coatings, the electrochemical tests generally reveal that the as-sprayed metal coatings could not provide the substrate with effective and reliable protection from corrosion due to the existence of unbonded lamellar interfaces (Ref 25, 26). Moreover, limited bonding also degrades the wear performance of hard alloy coatings since lamella spalling occurs easily through the 
propagation of sub-surface cracks along the lamellar interface at high stress conditions (Ref 24, 27), especially as the coatings are subjected to dynamic loading (such as cavitation erosion) (Ref 28). Hiraga et al. reported that compared with vacuum plasma-sprayed NiTi coating the laser remelting treatment leading to the formation of bulklike NiTi presented the enhanced cavitation erosion resistance by a factor of magnitude from one order to over two orders (Ref 29,30). This makes certain traditional thermal spray applications to be possibly replaced by other surface engineering processes such as diffusion processes, cladding processes for more reliable protection (Ref 26). Therefore, many efforts have also been made to increase the cohesion of metal coating toward bulk-like ones, since a limited cohesion does not make metal coating corrosion-resistant (Ref 25) and wear-resistant (Ref 24, 25).

Due to limitations of current spraying processes to directly deposit bulk-like metal coatings, post-spray treatments are used to eliminate pores in the coating and achieve metallurgical bonding to the substrate. Main processes include spray-fusing, high temperature annealing treatment, laser remelting, and so on. The spray-fusing process was invented along with self-fluxing alloys in the early of last 1950s, applying only to self-fluxing alloys (Ref $1,12,31)$. Its main features will be mentioned in the later section. Since atom diffusion occurs across the intersplat and coating/substrate boundaries at high temperature, the post-spray heat treatment usually leads to healing of unbonded interface boundaries and reducing of small pores in the coating (Ref 32, 33). For metallic coatings especially MCrAlY bond coats for thermal barrier coatings, high temperature heat treatment in vacuum or inert gas atmosphere not only leads to full densification of the bond coat itself but also the formation of metallurgical bonding between the superalloy substrate and the bond coat (Ref 34,35 ). The HIP (hot isostatic pressing) treatment is more effective to densify metallic coatings (Ref 32,33 ). The heat treatment needs to be carried out at a high temperature either in a vacuum chamber or in a controlled inert atmosphere. Moreover, the part size is practically limited by the size of the chamber. Meanwhile, the heat treatment does not apply to the parts sensitive to high temperature.

Laser remelting has been applied to different types of thermal spray coatings (Ref 36, 37). For metallic coatings, pores in the coating can be removed after laser remelting to form a fully dense coating for complete protection of substrates from corrosive media (Ref 38-40). Moreover, the potential high performance of metallic coating materials under dynamic wear conditions such as cavitation can be fully taped out by producing bulk-like coating rather than lamellar-structured coatings (Ref 29, 30). For ceramic coatings, despite laser densification of coatings presenting bulk-like microstructure, rapid cooling of remelted coating inevitably produces cracks perpendicular to the coating surface to form crack-networks (Ref 41). Fortunately, such vertical crack network perpendicular to coating surface could be effectively utilized to enhances strain tolerance of YSZ thermal barrier coatings during thermal cycling (Ref 42, 43).

Despite the effectiveness of post-spray heat treatment to convert the porous coating to bulk-like one, the ultimate challenge is to directly deposit bulk-like metallic coating by thermal spraying. A recent investigation showed that $\mathrm{NiCr}$ alloy coating with a lamellar bonding ratio higher than $80 \%$ can be deposited with powder design by shrouded plasma spraying (Ref 44). Since enhanced adhesion and cohesion with low oxide inclusion makes the coating ductile, the post-spray mechanical shot-peening was applied to alloy coating to achieve fully dense coating with pore sealing and to prevent the penetration of the aqueous solution. It was also found that by taking advantages of low melting point of self-fluxing alloys and utilizing in-situ deoxidizing effect of in-flight molten droplets bulk-like metal coatings are achieved by atmospheric plasma spraying (Ref 45, 46).

In conclusion, the present paper will focus on recent research progresses in the metallurgical bonding development in plasma spraying for depositing bulk-like metal coatings. The general strategies to develop metallurgical bonding will be reviewed. Then, the approach to create the spread-fusing effect for a self-bonding mechanism by highly over-heated molten droplets will be introduced with the illustration of typical coating properties. The development of the in-situ deoxidizing mechanism of in-flight molten droplets in an open ambient atmosphere will also be presented suggesting the possibility to deposit the bulk-like metal coatings by APS. In the interest of brevity, this review concentrates mainly on the bonding formation in the like-on-like system of metal coating, i.e., the cases that the metal droplet impacts on the metal substrate with the same compositions as that of droplet.

\section{Strategy for Bulk-Like Dense Metal Coating Formation Through Deposition Temperature Control}

\section{Effect of Substrate Preheating on the Characteristics of Metallic Splat Formation and Coating Adhesion}

Three types of bonding mechanisms contribute to the adhesion and cohesion of thermal spray metal coatings. They are known as mechanical bonding in the form of mechanical interlocking of the roughened surface, physical bonding due to Van der Waals force, and metallurgical 
bonding through an alloying or chemical reaction (Ref $5,6,47)$. It should be pointed out that when oxides are included in the metallic coating the chemical bonding via a covalent bond or an ionic bond may also exist at the local oxide-metal interface (Ref 48). However, in most cases oxide inclusions hinder the bonding formation (Ref 4,49 ). It should be noted that metallurgical bonding is the strongest one among all three bonding mechanisms for metallic coatings. Thus, how to create an effectively metallurgical bonding at the interface between the substrate and the coating, and interfaces among splats during molten droplet impact is the main challenge accompanying the development of thermal spray processes up to date.

As a first mechanism, the metallurgical bonding can be achieved by the wetting of the molten metal to the substrate surface at a low interface temperature as those observed in soldering and brazing processes (Ref 50). When the interface temperature exceeds the melting point of the substrate, the bonding is formed by spread-fusing as those in welding (Ref 6). Since the bonding is formed during spreading after molten droplet impacts on the substrate, the bonding formation in thermal spray metallic coating was widely examined through the splat formation process (Ref 51). When a molten metal droplet impacts on a metal substrate at a high velocity from several tens of meters to a couples of hundred meters per second, lateral spreading of molten melt onto the substrate surface completes in about one microsecond and its solidification completes in less than ten of microseconds (Ref 52-54). Accordingly, the bonding at the interface between spreading melt and the substrate needs to form before the solidification of melt in contact with the substrate starts either through fusing or wetting. Clearly, the time available for the bonding development at the interface is in order of less than ten of microseconds. The post-spray fusing of self-fluxing alloy coatings as a post-spray treatment process can be considered as a typical solid/liquid metal bonding process through wetting although the metallurgical bonding is not generated during the spreading process of molten spray particles. Moreover, the dynamic contact pressure acts only in a region of the flattening ratio less than two (Ref 23). Thus, at the most interfaces between the splat and substrate there is no effective dynamic contact pressure.

The bonding formation theory in the brazing process is similar to the thermal spray bonding formation between melt and solid in which the heat transfer from the spreading molten droplet to the substrate cannot cause the melting of the substrate surface layer. In such a case, the oxide scale inevitably present on the metal substrate surface hinders effective joining, also during brazing the removal of oxide scale by certain flux is generally required for filler metal to bond with the base metal metallurgically by wetting (Ref 55). It is known that a flux reacts not only with the oxide scale but also corrosively attack the base material through dissolution and thus dispersion of oxide tarnish. However, since the normal reaction of flux with oxide scale takes place in a time scale of seconds in conventional brazing process, it is difficult to utilize a flux to improve the adhesion and/or cohesion of thermal spray metal coating regarding solidification time of a splat less than $10 \mu \mathrm{s}$. In the case that the effect of oxide scale is negligible like brazing in a controlled atmosphere, the wetting of molten filler metal to a solid surface leads to a metallurgical bonding formation, consisting of molten filler metal lateral spreading and subsequent dissolution of atoms into a melt. Since the dissolution involves the interaction of atoms in the solid surface with the atoms in the melt, it can be considered that the dissolution kinetics plays a key role in the bonding formation, which usually depends on the interface temperature and the contact time of melt with solid surface (Ref 56). Due to very limited time for wetting during spreading of impacting droplet, it can be considered that the bonding formation depends primarily on melt/solid interface temperature. The higher the interface temperature is before the melt starts to solidify, the higher the possibility for melt to bond the substrate surface. Moreover, a high transient contact pressure benefits the bonding formation through enhanced intimate contact between the spreading melt and the substrate. A higher droplet velocity results in a higher contact pressure during droplet spreading (Ref 23). Generally D-gun coatings present a high tensile adhesion than plasma-sprayed coatings (Ref 5). Unfortunately, the high contact pressure upon the impact of molten droplets decays rapidly with lateral spreading. The effective transient contact pressure acts only in a central splat-substrate contact region less than two times of droplet diameter (Ref 23). Thus, for over $70 \%$ splat interface the maximum contact pressure is less than $1 \mathrm{MPa}$, which is much lower than the peak contact pressure of about $1000 \mathrm{MPa}$ at the central region of splat upon impact (Ref 23 , 57). Thus, the bonding formation depends on the interface temperature at the majority of the splat-substrate interface.

Since the interface temperature is determined by both the substrate surface temperature and the droplet temperature, the effect of substrate preheating on the bonding formation was much concerned in the last three decades (Ref 51). The experimental investigations showed that increasing the substrate temperature prior to coating deposition, hereafter referred to as the deposition temperature, is effective to improve the adhesive strength of thermal spray coatings (Ref 58-60). The first effect of increasing the deposition temperature by preheating the substrate is to achieve a regular disk splat with reduced weakly attached radial arms or small droplets (Ref 61-63). Its second effect can be attributed to the improvement of 
intimate contact of the splat with the substrate due to the removal of the surface adsorbates (Ref 64-66). Then, the third effect is to activate the surface and thus promote the reaction between splat and substrate (Ref 59, 67, 68). Accordingly, the adhesion of thermal spray coatings increases with increasing the preheating temperature (Ref 58-60). However, since the preheating also promotes the oxidation of the metal substrate, it was believed that a higher preheating temperature leads to a thicker oxide scale. It not only reduces adhesion through fracture inside substrate metal oxide layer (Ref 69), but also reduces the possibility to form the metallurgical bonding (Ref 49). The surface oxidation influences little on the formation of regular disk type splats when the oxidation-induced surface roughness increment (Ref 70) and gas entrapping effects (Ref 71) can be neglected on the spreading. The higher adhesive strength obtained at a higher preheating temperature is attributed to improved intimate contact and lower solidification rate which gives melt a longer time to flow into surface cavities (Ref 59). On the other hand, it was also noticed that the oxidation of the substrate surface to a certain degree benefits the improvement of adhesive strength of thermally sprayed ceramic coatings (Ref 58). Thus, increasing the deposition temperature in the ambient atmosphere enhances coating adhesion at the expense of excluding the metallurgical bonding formation for metal coatings. The adhesion of metal splats deposited on a preheated substrate up to $327^{\circ} \mathrm{C}$ still mainly depends on mechanical interlocking since the adherent splat can be simply detached from the substrate for the microstructure examination from the bottom of the splat surface (Ref 72, 73). Even using the substrate with a gold coating or depositing splat in an $\mathrm{N}_{2}$ atmosphere to prevent the substrate from oxidation the adhesion of splat was almost the same as that sprayed on the bare substrate in the open air (Ref 74). Although the possible interaction layer formation at splat/substrate interface in the local central region by melting or diffusion for like-on-like splat/substrate system was also reported (Ref 75), it can be inferred that to remarkably enhance the adhesion through metallurgical bonding, a much higher deposition temperature is required. However, most researches investigating the effect of preheating temperature on splat formation were concerned only with the disk-like splat formation by suppression of splashing through removing evaporable adsorbates and very few investigations reported the formation of good interface bonding across the boundary (Ref 76). This is because most investigations on splat formation were carried out at ambient atmosphere and its effect was limited by the inevitable substrate oxidation. Consequently, the splat formation investigations up to now still did not reveal at what preheating temperature a strong metallurgical bonding can be achieved through liquid/solid reaction at the interface. This can be partially attributed to a great number of materials combinations of substrate and splat, which leads to complexity of problems. Therefore, to make it simple, the following sections will more focus on the droplet/substrate combinations of the same material, which is similar to what happens in adjacent splats within the coating.

\section{Interface Temperature Requirements for the Intersplat Bonding Formation}

For oxide ceramics, it was found through like-on-like experimental design that the critical interface temperature for spreading melt to form a strong bonding is equal to the glass transition temperature of spray material (Ref 68, 77). Only when the interface temperature exceeds the critical interface temperature, the spreading melt could bond to the underlying splat in solid-state chemically since the atoms in melt have sufficient activity due to its low viscosity. Supposing that $\mathrm{Al}_{2} \mathrm{O}_{3}$ spray particles are heated to a temperature just over its melting point, a critical deposition temperature of approximately $300{ }^{\circ} \mathrm{C}$ is required to form the chemical bonding at the splat boundary following the above theory (Ref 68). This is consistent with the reported preheating temperature of $\mathrm{Al}_{2} \mathrm{O}_{3}$ substrate temperature over which the deposited $\mathrm{Al}_{2} \mathrm{O}_{3}$ splats were bonded to the plasma-sprayed alumina substrate with $\gamma$-phase (Ref 78 ). Moreover, through the controlled oxidation in the $\mathrm{CO}_{2}$ atmosphere to form an $\mathrm{FeO}$ layer on carbon steel substrate (Ref 79) with a thickness of about one ceramic splat, from the results reported by Valette et al. (Ref 79) it can be found that the alumina coating deposited at the deposition temperature higher than the critical bonding temperature presented the adhesion higher than $60 \mathrm{MPa}$. Recently, Valetter et al further reported an adhesion of $105 \mathrm{MPa}$ for alumina coating deposited in the same fashion on the flat pure nickel substrate with an $\mathrm{NiO}$ layer (Ref 80). The fact that the deposition temperatures in the investigations mentioned above (Ref 79,80$)$ are higher than the critical bonding temperature reported (Ref 68) reveals the dominant effect of the interface temperature on the interface bonding formation between the similar materials. Since the critical bonding temperature here is referred to as the critical deposition temperature and is proportional to the melting point of oxide ceramic spray materials (Ref 68), the critical preheating temperature for certain ceramics can be simply estimated.

Although with common metal alloys the critical interface temperature was not defined yet for the bonding formation, it can be supposed that the critical bonding temperature may be related to the lowest interface temperature for splat to maintain the liquid state. If the interface temperature is lower than such temperature, the 
bonding formation needs to take place at the solid/solid interface from which a strong metallurgical bonding is not expected. Thus, the critical bonding temperature can be estimated by the maximum undercooling temperature of molten metals. It has been reported that the maximum undercooling temperature of most metals except refractory metals is less than $400{ }^{\circ} \mathrm{C}$ (Ref 50). This implies that to form a metallurgical bonding through melt/solid wetting mechanism the maximum interface temperature between spreading melt and underlying substrate should be higher than $\sim 1100{ }^{\circ} \mathrm{C}$ for pure $\mathrm{Ni}, 1200{ }^{\circ} \mathrm{C}$ for pure iron, and $1300{ }^{\circ} \mathrm{C}$ for pure titanium regarding their melting points. These interface temperature requirements are nearly comparable to or higher than those reported for $\mathrm{Al}_{2} \mathrm{O}_{3}$ and $\mathrm{TiO}_{2}$ (Ref 68). Regarding higher thermal conductivity of metals than oxide ceramic materials, the critical deposition temperature for metal splat to form metallurgical bonding could be higher than those for ceramics.

\section{Bulk-Like Metallic Coating Formation Through Vacuum Plasma Spraying}

To fulfill the interface temperature requirement for the bonding formation either increasing the substrate surface temperature or increasing droplet temperature is generally required. Since increasing the substrate temperature results in the oxidation of the substrate or the previously deposited splat surface exposed to open air, this approach is generally not realistic to promote the metallurgical bonding for thermal spray processes in an ambient atmosphere such as APS. However, the previous deposition practices under vacuum spray conditions proved the effectiveness to deposit the bulk-like metal coating by controlling the deposition temperature (Ref 81-83). It was reported that the tensile strengths of both $\mathrm{Al}-\mathrm{Si}$ alloy and $\mathrm{Ni}-20 \mathrm{Cr}$ alloy deposits by vacuum plasma spraying are increased with increasing the deposition temperature (Ref 81). For Ni$20 \mathrm{Cr}$ alloy, when the deposition temperature was increased from about 660 to $960{ }^{\circ} \mathrm{C}$, the ultimate strength was increased from about 290 to $560 \mathrm{MPa}$, which is reasonably comparable to that of Ni20Cr bulk fabricated by laser additive manufacturing (Ref 84). When pure titanium coatings were deposited using two types of powders at a deposition temperature of $650{ }^{\circ} \mathrm{C}$, as shown in Fig. 1, their ultimate tensile strengths at room temperature are comparable to those of Ti-bulk materials and rolled Ti-plate and the strengths at high temperatures are even higher than the counterparts due to dissolution of oxygen (Ref 82). Figure 2 compares the mechanical properties of vacuum plasma-sprayed Inconel 625 nickel alloy at high deposition temperature with those of annealed wrought one (Ref 83). Inconel 625 deposit presented comparable mechanical properties with that of the annealed bulk counterpart. It was

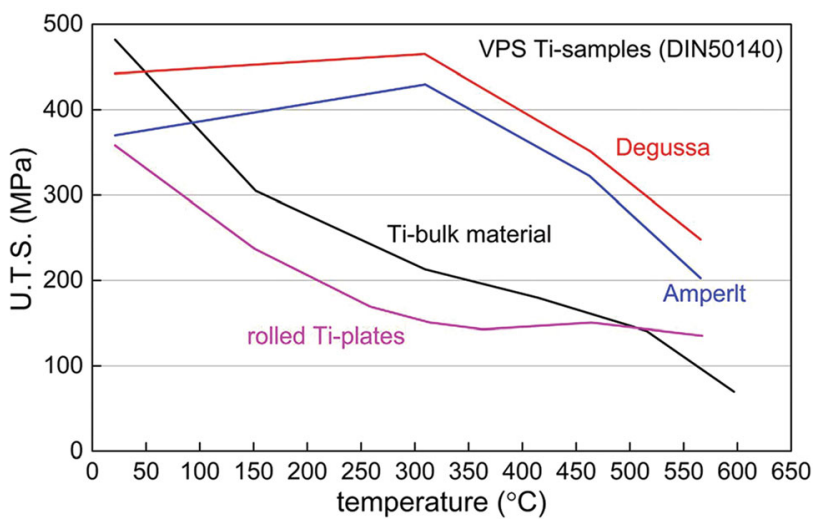

Fig. 1 Comparison of the tensile strength of vacuum plasma-sprayed bulk-like $\mathrm{Ti}$ deposit with those of bulk $\mathrm{Ti}$ materials against test temperature. The Ti deposits were sprayed with two types of powders (Degussa and Aperit). (Ref 17)

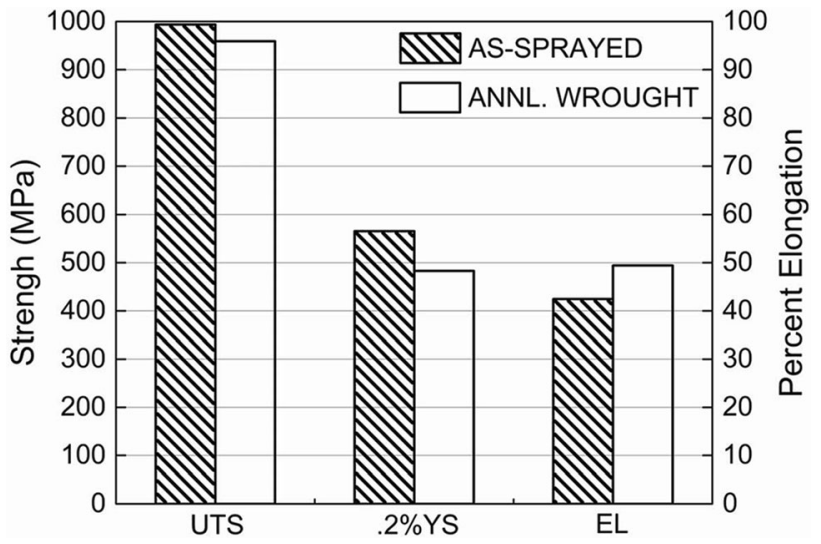

Fig. 2 Comparison of mechanical properties of vacuum plasmasprayed bulk-like In-625 nickel alloy deposit with annealed wrought In-625 alloy. (Ref 18)

also found that the cavitation performance of vacuum plasma-sprayed NiTi at a deposition temperature of $750{ }^{\circ} \mathrm{C}$ is comparable to bulk counterpart (Ref 85), although high deposition temperature makes the interpass surfaces more sensitive to oxidation by residual oxygen in the chamber (Ref 86). All those facts reveal that by controlling the deposition temperature to higher than a temperature from $660{ }^{\circ} \mathrm{C}$ up to $960{ }^{\circ} \mathrm{C}$ excluding the effect of oxidation, bulk-like metal coatings can be deposited for Ti alloys and Ni-based alloys. Those results also clearly demonstrate that increasing the deposition temperature in terms of substrate temperature leads to the formation of sufficient lamellar metallurgical bonding in plasma-sprayed metal coatings. Here, the challenge is to determine the critical deposition temperature of a given spray material for metallurgical bonding formation upon molten droplet impact on the previously deposited splat surface leading to fabrication of bulk-like deposit to understand the role of wetting on the bonding formation. The second challenge is to control the 
plasma gas species dissolving into molten metal and oxide inclusion. This strategy does not apply to most common atmospheric plasma spraying of metal coatings since the high deposition temperature over $600{ }^{\circ} \mathrm{C}$ leads to severe oxidation of both the substrate and coating surface of each pass.

\section{Strategy for Developing Bulk-Like Metal Coating by Spread-Fusing Effect Through Creating Ultra- High Temperature Droplets}

\section{Metallurgical Bonding Formation at the Coating/ Substrate Interface}

When a metal coating is thermally sprayed in an ambient atmosphere, an oxide scale is inevitably formed on the splat surface (Ref 16, 87, 88). Since the formation of a metallurgical cohesive bonding can be achieved only when the coating surface layer is instantaneously melted by spreading molten melt, this mechanism is referred to here as the spread-fusing bonding. Such spread-fusing bonding mechanism was reported for the metallurgical bonding formation at the interfaces between molybdenum coating and different substrates of a lower melting point than molybdenum including steel, cobalt and $\mathrm{Ni}-\mathrm{Cr}$ alloy in early last $60 \mathrm{~s}$ (Ref 89). Later, during the early development of Ni/Al composite powder (Ref 90), it was pointed out that the impact of $\mathrm{NiAl}$ molten droplets on a steel substrate caused the formation of metallurgical bonding. It was demonstrated that the metallurgical bonding was created through melting of the substrate by the ultra-hot droplet due to an exothermic reaction between $\mathrm{Ni}$ and $\mathrm{Al}$. Kitahara (Ref 91) investigated the microstructures of the interface between a substrate and a plasma-sprayed coating for different substrate/coating combinations. The results revealed that when high melting point molten droplets impact on a substrate of a low melting point such as the splat-substrate combinations like W-Fe, Mo-Fe, Mo-Ni, Ta-Ni, Ni-Al, the spreading of molten droplets can cause the local substrate to melt, resulting in fusing to bond the splat metallurgically with the underlying substrate. The formation of the intermetallic compounds at the interface provided direct evidence of such spread-fusing bonding effect (Ref 92). All those early works demonstrated the possibility of forming metallurgical bonding at the interface between the substrate and the coating by molten droplet impact-induced melting. This phenomenon was also proved by molten crater generated on the steel substrate by impact of molten refractory metal Mo droplets (Ref 93).

Dallaire established the conditions for the incipient melting for different particle-substrate systems by analytically calculating the splat-substrate interface temperature for the materials of different types (Ref 94). Numerically, Li et al. (Ref 95) reported the interface temperature between the molten metal splat and the substrate for different droplet/substrate combinations. The numerical simulation was made by a simple one-dimensional heat transfer model through supposing that a thin layer of molten metal is instantaneously brought on a flat metal surface with the intimate contact. Theoretically, they showed that the impact of molten refractory metal droplet such as Mo, W, and Ta enables the melting of low melting point substrate such as iron and nickel. Those results agree with that reported by Dallaire and are also consistent with the experimental results reported previously by Kitahara (Ref 91). However, it was also pointed out that the spreadfusing does not occur to the like-on-like material combinations. For example, the impact of nickel or iron droplets does not cause incipient melting of nickel substrate or iron substrate, respectively (Ref 94). Consequently, the metallurgical bonding by incipient melting of impacting molten droplet could not be formed at the interfaces between the splats through the spread-fusing mechanism at ambient condition although few evidences for spread-fusing at a local central area with the like-on-like materials were reported (Ref 96). However, if a $\mathrm{Ni}$ alloy molten droplet can be over-heated to a temperature near the melting point of a refractory metal such as Mo its impact on the identical $\mathrm{Ni}$ alloy substrate could also cause the substrate surface melting although generating an ultra-hot molten droplet is another challenge.

\section{The Droplet Temperature Conditions for the Spread-Fusing Self-Bonding Formation at Ni-Based Alloy Intersplat Interfaces}

It is natural to consider that the substrate surface layer will be melted when the substrate surface region is heated to a temperature higher than its melting point by the impact of the molten droplet (Ref 94, 95). Therefore, whether the maximum interface temperature between the spreading melt and the substrate is higher than the melting point of the substrate materials can be taken as the criterion for estimating whether the spread-fusing takes place or not. The evolution of the interface temperature between the spreading molten metal and the substrate after a molten metal droplet impact can be numerically estimated by a simple one-dimensional heat transfer model through supposing that a thin layer of molten metal is instantaneously brought on a flat metal surface (Ref 95). Accordingly, as shown in Fig. 3 for Ni-based alloy droplets at different temperatures ( $\operatorname{Ref} 45)$, only when the droplet temperature is higher than $2400{ }^{\circ} \mathrm{C}$, the maximum temperature of the $\mathrm{Ni}$ substrate surface can be heated to a temperature higher than 


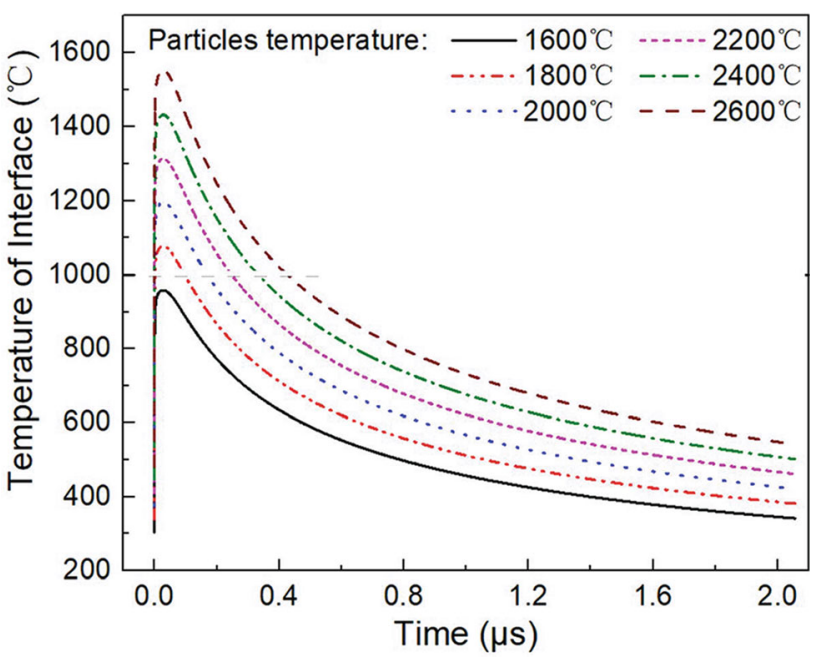

Fig. 3 The effect of droplet temperature on the simulated temperature evolution at the interface between molten splat and solid substrate for Ni-based alloy (Ref 29)

its melting point. Then, the Ni-based droplets having a temperature higher than $2400{ }^{\circ} \mathrm{C}$ are bonded to the identical underlying Ni-based splats through a liquid molten phase in the same fashion as that in metal welding. As a result, a metallurgical bonding is formed between the identical material splats through the spread-fusing selfmetallurgical bonding mechanism. These results indicate that the formation of the self-bonding requires the generation of the molten droplets having approximately $1000{ }^{\circ} \mathrm{C}$ higher temperature than its melting point. To reveal the metallurgical bonding formation at the interlamellar interface by high temperature molten droplet by spread-fusing, the splat deposition test was carried out by a Ni-based alloy molten droplet at a temperature above $2620{ }^{\circ} \mathrm{C}$ on the polished flat In738 alloy substrate. This is because In738 alloy has similar thermophysical properties with $\mathrm{NiCrMo}$ alloy. The examination into a cross section of splat revealed that a crater in the substrate was present underneath the splat revealing that the splat was welded to the substrate (Fig. 4) (Ref 97).

For low melting point materials with a high boiling point, it can be expected to acquire molten droplets with much higher overheating temperatures. For pure Al, the simulation shows that when the droplet temperature is higher than $1800{ }^{\circ} \mathrm{C}$ the $\mathrm{Al}$ substrate surface can be heated to a temperature higher than its melting point by $\mathrm{Al}$ molten droplets (Fig. 5) (Ref 98). The measurement of Al particle temperatures during plasma spraying reveals that most $\mathrm{Al}$ particles are heated to a temperature higher than $1800{ }^{\circ} \mathrm{C}$ (Fig. 6) (Ref 98), which is a minimum temperature necessary for creating the spread-fusing self-bonding. Although the $\mathrm{Al}$ splat was deposited on a well-polished $\mathrm{Al}$ alloy substrate the interface reveals a wave profile (Fig. 7)

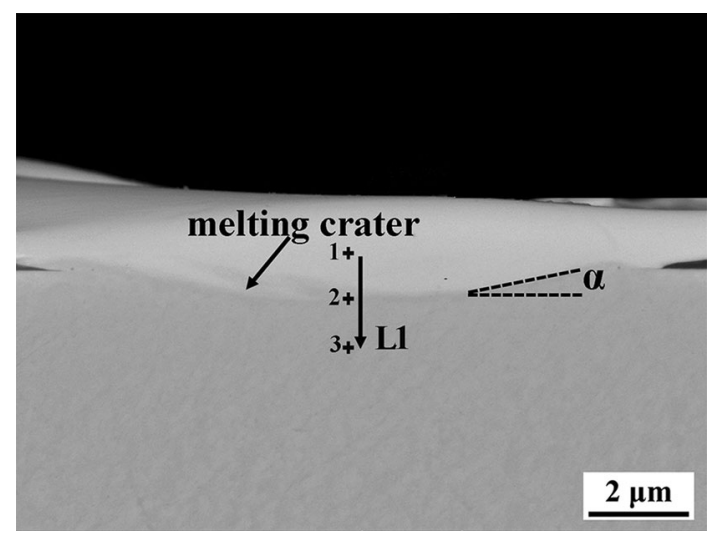

Fig. 4 Cross section of NiCrMo splat deposited on the polished flat In738 nickel alloy substrate by NiCrMo droplet having a temperature higher than $2620^{\circ} \mathrm{C}$, showing the crater on the substrate generated by impacting NiCrMo droplet and welding of the splat to the substrate (Ref 97)

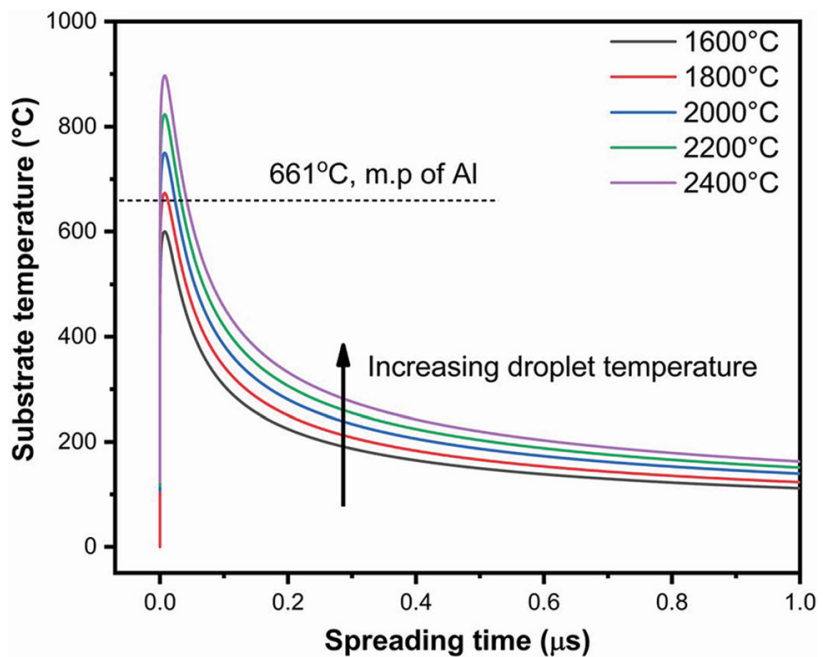

Fig. 5 Effect of molten $\mathrm{Al}$ droplet temperature on the interface temperature evolution between $\mathrm{Al}$ molten splat and $\mathrm{Al}$ solid substrate (Ref 98)

(Ref 98) indicating the mixing of splat in a molten state with the melted substrate surface layer. Accordingly, during $\mathrm{Al}$ coating deposition, the self-bonding through the liquid phase demonstrates that droplet temperature fulfills the requirement for generating spread-fusing. This fact further reveals that the molten droplet temperature for the spread-fusing self-bonding can be estimated theoretically and self-bonding between like-on-like intersplat interfaces can be created through controlling droplet heating. Paredes et al investigated the effect of the substrate preheating on the adhesion of thermally sprayed Al coatings (Ref 99). Their results showed that plasma-sprayed Al coating at an ambient atmosphere without preheating fulfilled the standard requirements for application, while flame spraying must be performed with the substrate preheating to comply 


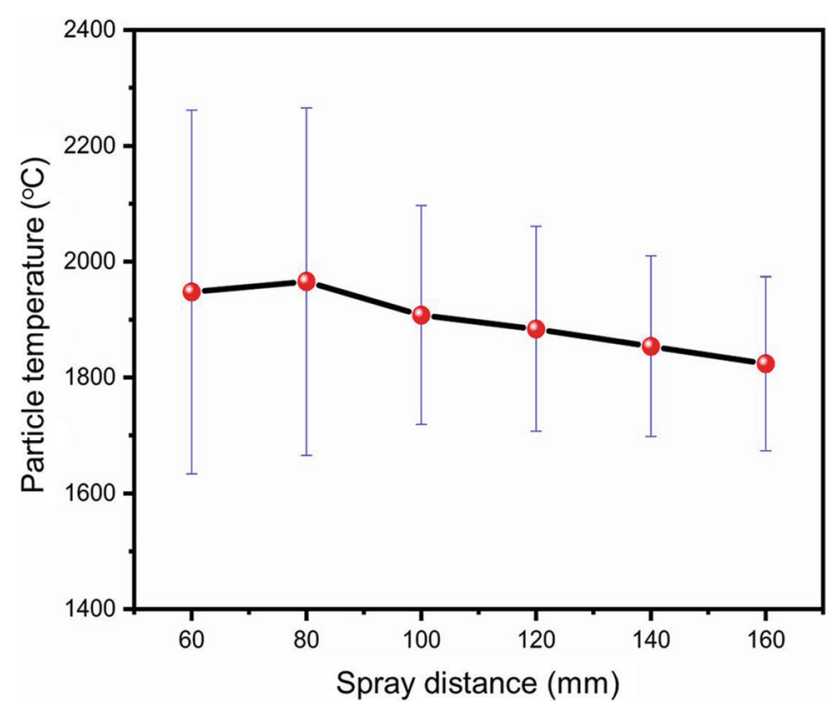

Fig. 6 Change of $\mathrm{Al}$ in-flight spray particle temperature in plasma jet against spray distance (Ref 98)

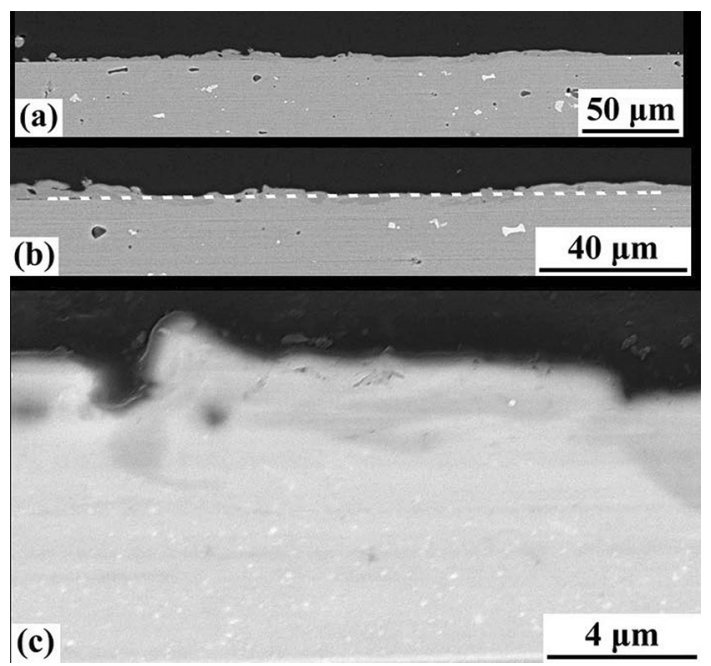

Fig. 7 Morphology of Al splat deposited on a polished flat Al alloy substrate at a low magnification (a), showing flat reference surface profile (b), and showing wavy interface between splat and substrate with an evident contrast (Ref 98)

with the adhesion standard. Thus, the incipient melting of the substrate surface depends on the temperature of both the droplet and the substrate. A lower molten in-flight particle temperature requires a higher preheating temperature provided that preheating does not cause adverse effect due to oxidation. However, practically, the oxidation of in-flight spray molten particles hinders the formation of metallurgical bonding in a large part of the splat interface in the coating. One challenge to apply the spread-fusing self-bonding mechanism is how to develop oxide-free droplets in the ambient atmosphere.

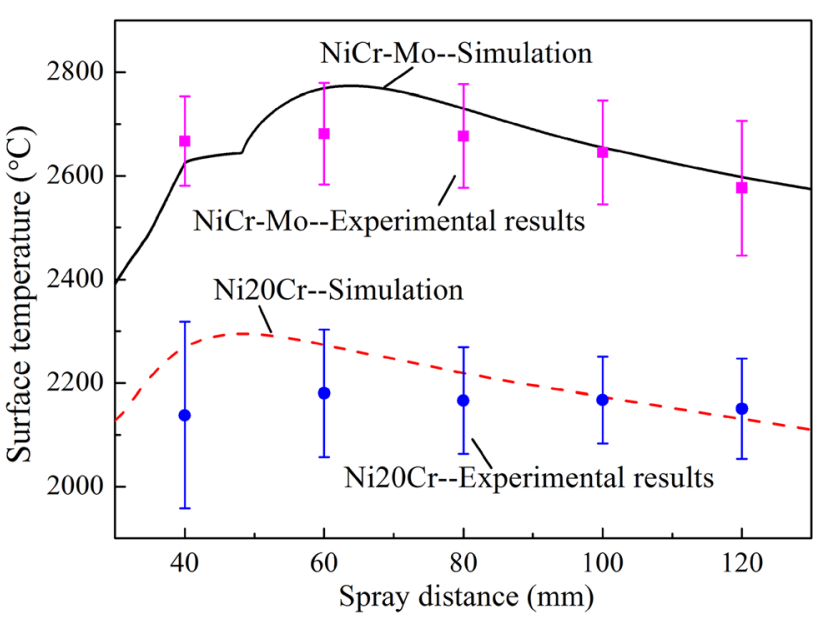

Fig. 8 Significantly enhanced heating effect on the molten Ni-based alloy droplet with plasma jet by Mo cladding on $\mathrm{Ni20Cr}$ powder particles, showing more than $500{ }^{\circ} \mathrm{C}$ increase compared to bare Ni20Cr particle (Ref 102)

\section{Bulk-Like Coating Deposition Through Creating Ultra-Hot Molten Droplets}

When thermal spray particles are heated to a molten state, vaporization occurs. With the increase of the droplet temperature the vaporization rate increases and reach the maximum until the evaporation starts when the surface temperature reaches to the boiling point (Ref 100). On the other hand, vaporization or evaporation brings out a strong cooling effect to particle heating and limits the heating up of molten droplet. The modeling results show that the effective heat transfer coefficient decreases with the increase of molten droplet temperature. The reduction of heat flux from the plasma jet to the particle due to evaporation can exceed $50 \%$ when the temperature is close to the boiling point of spray material (Ref 101). For most nickel base alloy droplets generated by by HVOF or by plasma spraying, it is hard to find out the experimental data for molten Ni alloy droplets up to now to have a temperature higher than $2200{ }^{\circ} \mathrm{C}$. As a result, only a limited splat interface bonding is present in a thermal spray Ni-based coating, especially at the interface between two adjacent passes. Within one spray pass, the critical droplet temperatures for incipient melting could be reduced because the splat may not cool down to room temperature during coating deposition.

Recently, a novel powder design approach was proposed to ensure the generation of molten Ni-based alloy droplets of a temperature higher than $2400{ }^{\circ} \mathrm{C}$ by suppressing element vaporization induced cooling effect (Ref 97). In this approach, Ni-based alloy powder particle is cladded with a Mo surface layer to construct a core-shell-structured 
particle. Figure 8 shows typical results of droplet temperature evolution during in-flight for Mo-clad Ni20Cr particles (Ref 102). It can be found that these novel structured $\mathrm{Ni}$-based alloy powder particles are heated to a temperature of over $2650{ }^{\circ} \mathrm{C}$, higher than the critical temperature of $2400{ }^{\circ} \mathrm{C}$ for spread-fusing, being over $500{ }^{\circ} \mathrm{C}$ higher than the temperatures of traditional $\mathrm{Ni} 20 \mathrm{Cr}$ particles. It should be noticed that this high temperature is even close to the boiling point of alloying element $\mathrm{Cr}\left(2670{ }^{\circ} \mathrm{C}\right)(\operatorname{Ref} 103)$, which can be considered to be the highest temperature that molten Ni20Cr particles can reach. Accordingly, such droplets are referred to as ultra-high temperature droplets (UHTD). When this powder design was applied to stainless steel, the Mo-cladded stainless steel powder particles could be also heated to a similar temperature to that of Mocladded NiCr powder particles (Ref 104).

The microstructure of NiCrMo alloy coating deposited using Mo-cladded Ni20Cr powders by shrouded plasma spraying is shown in Fig. 9. The coating has an apparent porosity of only $0.16 \%$ and is much denser than the conventional $\mathrm{NiCr}$ coating (Ref 97). The microstructure characterization at the regions near the interface between the stainless steel substrate and the NiCrMo coating and intersplat interfaces within the coating by EBSD revealed the metallurgical bonding formation (Fig. 10) (Ref 97). Since both the stainless steel substrate and the Ni-based alloy coating have the same FCC crystalline structure, the epitaxial grain growth of splats based on the grains of the polished stainless steel substrate is well observed based on the EBSD analysis results (Fig. 10b). Thus, the adhesive strength of the coating is higher than $70 \mathrm{MPa}$ with a fracture that occurred in adhesives during the tensile test. The EBSD analysis also reveals the continuous grain growth across several splats (Fig. 10d) within the coating (Fig. 10c), which indicates the metallurgical bonding formation at the intersplat boundaries.

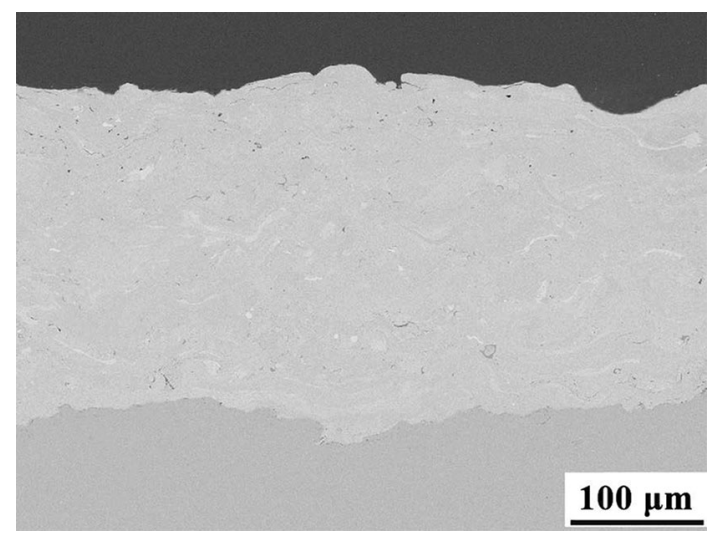

Fig. 9 Typical dense microstructure of NiCrMo coating shrouded plasma-sprayed by using Mo-clad Ni20Cr powders (Ref 97)
The erosion wear of thermal spray coating, especially under the test condition by the normal impact of erodent, is very sensitive to the lamellar interface bonding. The shockwave effect induced by the repeated impacts of the erodent causes crack propagation along the interface boundaries between the splats exposed directly to erodent and the subsurface splats. Figure 11 shows a typical example of cracks observed in HVOF cobalt coating with an initial thickness of about $250 \mu \mathrm{m}$, experienced the erosion test under the normal impact. Such cracking results in debonding of the deposited splats exposed to the top surface, making the coating eroded in a layer by layer fashion. Thus, the erosion wear resistance is well linearly related to the mean bonding ratio of plasma-sprayed brittle $\mathrm{Al}_{2} \mathrm{O}_{3}$ coatings (Ref 105). During erosion wear test of bulk materials, the dependency of the wear rate of ductile metallic materials on the impact angle of erosive particles presents a completely different characteristic from typical brittle ceramic materials (Ref 106). It is well known that the ductile materials present a peak erosion wear rate in an impact angle range from $15^{\circ}$ to $\sim 30^{\circ}$ and then decrease with the increase of the impact angle. On the other hand, the erosion rate of brittle materials increases with the impact angle and reaches the maximum at the angle of $90^{\circ}$, i.e., the normal impact of erodent on the material surface. For most thermal spray brittle ceramic coatings, it is reasonable that the erosion rate increases with the impact angle. For thermal spray metal coatings, when they are subjected to normal erodent impact they would be expected to present excellent wear resistance with less erosion rate than that a high impact angle. However, most investigations into the impact angle effect reveal completely different results (Ref 107-109). Haugen et al. (Ref 107) reported that thermal sprayed Stellite, boronized Stellite, cobalt-based coatings presented high or comparable erosion rates at $90^{\circ}$ with those at $22.5^{\circ}$, while electroplated $\mathrm{Ni}$ coatings, bulk carbon steel, and stainless steel exhibited a higher erosion rate at $22.5^{\circ}$ than $90^{\circ}$, being consistent with that observed for a ductile material. Clark et al. (Ref 109) also reported erosion behavior of different coatings sprayed by HVOF, APS, arc spraying at two typical different angles of $20^{\circ}$ and $90^{\circ}$. The results showed that the erosion resistance of HVOF metallic coatings at $90^{\circ}$ is close to that at $20^{\circ}$, while the erosion of laser-clad Armacor coatings at $20^{\circ}$ is much higher than those at $90^{\circ}$, behaving as bulk ductile metallic materials. Therefore, for most thermal spray metallic coatings, the oxide inclusions and limited lamellar interface bonding make the coatings behavior under erosion conditions more like brittle materials despite the ductile characteristics of the materials themselves. This feature is also obvious for plasma-sprayed Ni20 Cr coatings shown in Fig. 12 (Ref 110). When the test was applied to a casted bulk IN738 nickel-based alloy under the same 
Fig. 10 The grain structure near the interface between the NiCrMo coating and stainless steel substrate analyzed by EBSD (b) at the interface region marked in (a), showing the epitaxial grain growth across the interface by impact-induced substrate fusing; (c) and (d) show the microstructure within the coating and the grain morphology presenting the grain growth state across multiple of splats indicating the metallurgical bonding formation within the coating by EBSD, respectively

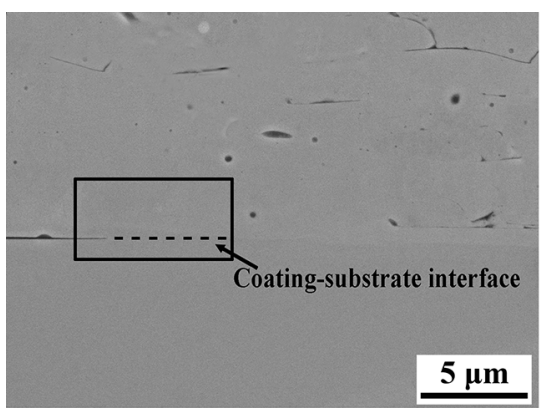

(a)

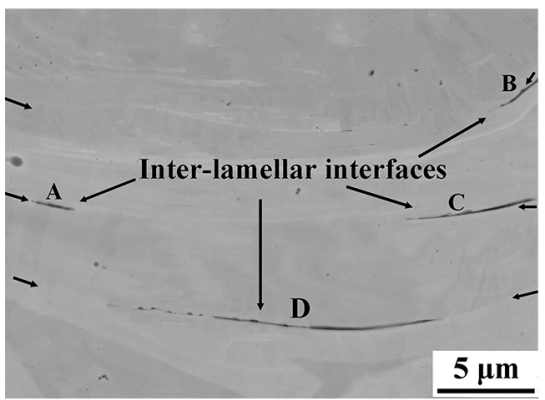

(c)

(d)

(b)
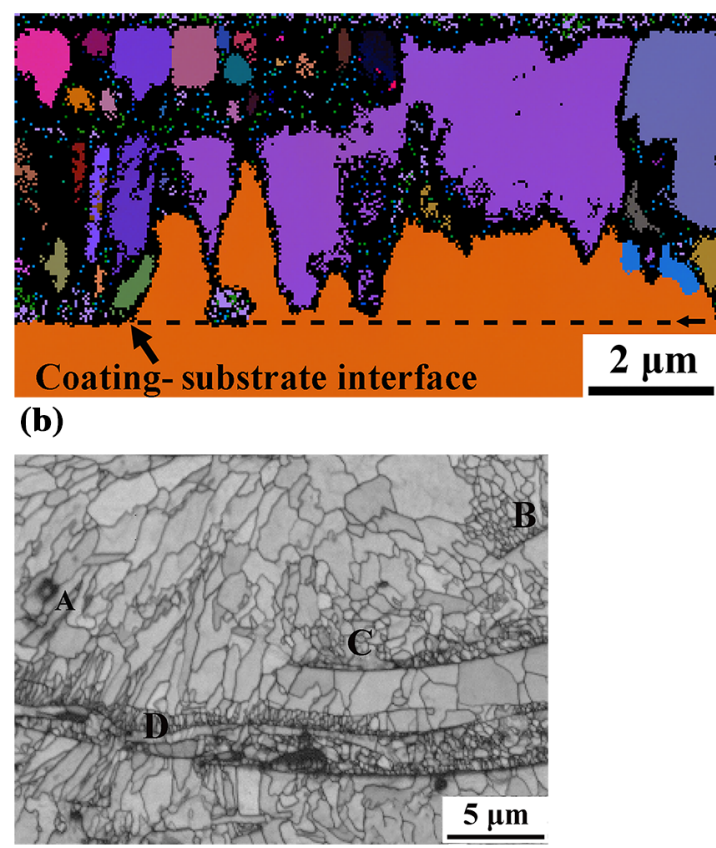

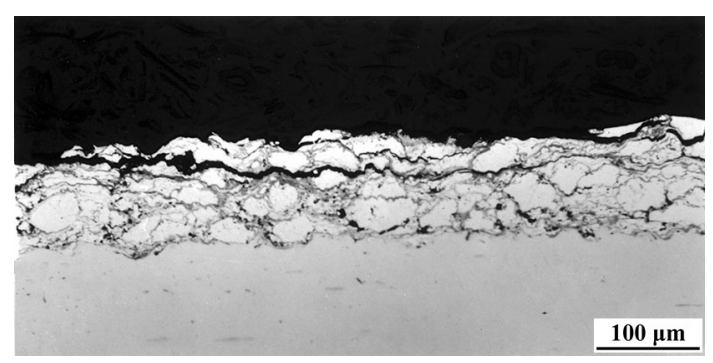

Fig. 11 Cross-sectional microstructure of HVOF-sprayed cobalt coating after subjected to erosion test at an impact angle of $90{ }^{\circ} \mathrm{C}$, showing the crack propagation along the interfaces of the splats exposed to near the surface layer leading to the debonding of splats and subsequently erosion of coating

condition, a typical relationship between erosion rate and impact angle for ductile materials was observed as shown in Fig. 12. On the other hand, the erosion test of the Nibased alloy coating deposited based on the spread-fusing bonding mechanism presents the same erosion behavior as that of a casted bulk IN738 in terms of the erosion rate against the erosion angle (Ref 110). Most importantly, the coating presents a ductile characteristic rather than brittle feature, which can be clearly recognized from the results in Fig. 12. Those facts indicate that a mechanically bulk-like metallic coating is deposited, indicating that the excellently strong bonding is formed at the interlamellar interfaces. The strong intersplat bonding makes the coating present a similar erosion behavior with that of bulk In738.

The ductile and excellent intersplat bonding characteristics allow application of the post-spray shot-peening to the as-sprayed coating to remove tiny pores which are

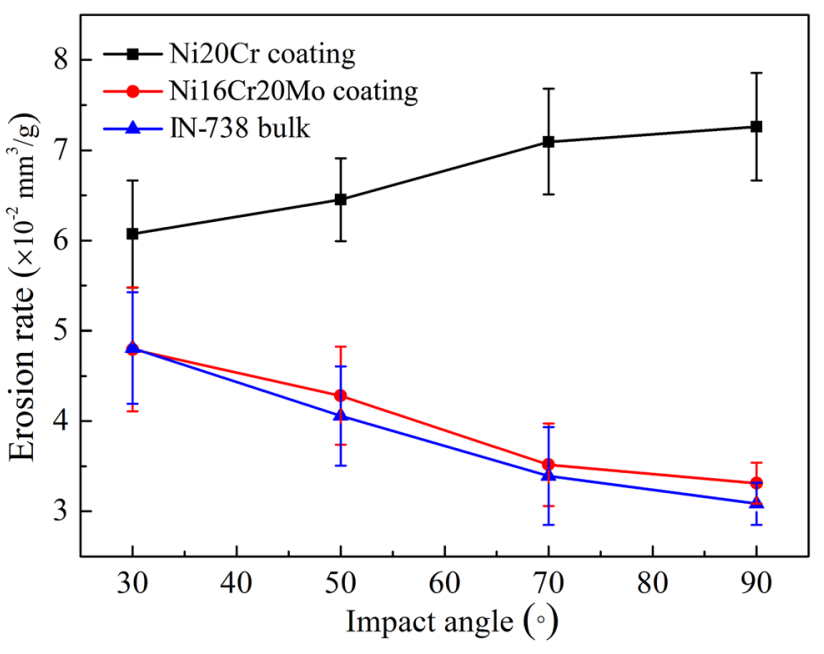

Fig. 12 Comparison of the dependency of the erosion rate of Ni16Cr20Mo coating plasma-sprayed using Mo-clad Ni20Cr powders on the erodent impact angle with those of casted IN-738 bulk and conventional Ni20Cr coating showing the IN-738-like behavior of NiCrMo coating under erosion wear conditions (Ref 110)

present in the coating as the unbonded splat interfaces at the periphery of splats. This treatment generates a fully dense Ni-based coating through which corrosive liquid or gaseous substance penetration cannot occur and consequently, complete corrosion protection of substrate is realized (Ref 44).

For austenitic stainless steel, it was also confirmed that using Mo-cladded powders ultra-high temperature droplets of $\sim 2650{ }^{\circ} \mathrm{C}$ can be generated. Accordingly, a dense coating is deposited by shrouded plasma spraying (Fig. 13) 


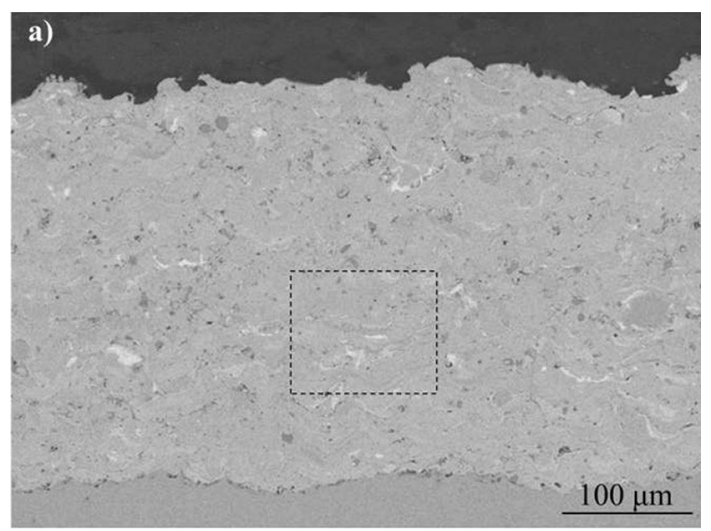

Fig. 13 Typical dense microstructure of SS304-Mo coating shrouded plasma-sprayed by using Mo-clad SS304 stainless steel powders (Ref 104)

(Ref 104). Thus, for most commonly used nickel-based alloys and iron-based alloys a bulk-like coating can be produced by plasma spraying of refractory metal cladding shell-core powders.

\section{Strategy for Generation of Oxide-free Molten Metal Droplets in Open Ambient Atmosphere by In-Situ Deoxidizing Effect}

\section{Thermodynamics of Oxide-Free Molten Metal Droplets Generation}

From the results mentioned above, it is clear that the spread-fusing effect leading to the metallurgical bonding formation at the splat interfaces can be developed through generating molten metal droplets with a highly over-heated temperature. However, severe in-flight oxidation leads to a great amount of oxide inclusions which hinder the metallurgical bonding formation across intersplat interfaces when the spraying is carried out in an open ambient atmosphere. Generating oxide-free molten metal droplets and maintaining their oxide-free state in an open ambient atmosphere is a great challenge.

Generally, the oxidation of metal in thermal spraying can be divided into two stages or two mechanisms, i.e., the oxidation of metal particles during in-flight and the postdeposition oxidation after droplet impacts on the substrate (Ref 16, 111). They can be referred to as in-flight oxidation and post-deposition oxidation, respectively. In-flight oxidation degree depends on particle size (Ref 111), droplet conditions (Ref 87, 88) and spray distance as well (Ref 112-116). For the in-flight oxidation, since the oxidation occurs successively during in-flight the resulting oxide inclusion content and subsequent oxygen content in the coating increase with the increase of the spray distance
(Ref 114-116). On the other hand, post-deposition oxidation depends on the temperature of the splats surface and/or coating surface exposed to the atmosphere during spraying (Ref 117).

With the in-flight oxidation, generally, the oxide inclusions are minimized through parameters optimization. As it is pointed (Ref 2), parameter optimization trends that minimize oxide inclusions include: (I) removing the reactive environment through the use of inert gas shrouds or chambers, (II) reducing the average temperature of spray particles, (III) reducing the dwell time of the particles by minimizing spray distance or increasing velocities, (V) using the proper large feedstock powder particle size. On the other hand, the in-situ deoxidizing can also be utilized to reduce oxide inclusions for certain spray materials. It was observed that the APS tungsten coating could present a very low oxygen content of $0.12 \%$ (Ref 118). This was attributed to the formation of $\mathrm{WO}_{3}$ with its low melting point of $1470{ }^{\circ} \mathrm{C}$ and evaporation temperature of $1840{ }^{\circ} \mathrm{C}$, which is lower than the melting point of tungsten and lead to rapid evaporation upon its formation during in-flight oxidation when tungsten particles are heated to melting (Ref 119). This kind of effect can be referred to as the insitu deoxidizing. Accordingly, it can be found that the APS W coatings usually present a low oxygen content of about $1 \%$ (Ref 120). Moreover, the APS W coating deposited by submicron-sized smaller particles presented a lower oxygen content than the counterpart by micron-sized larger powder particles despite a larger specific surface area of submicron-sized particles (Ref 121). This can be possibly attributed to the fact that smaller particles are heated to a fully molten state with a higher particle temperature, benefiting the evaporation of the formed oxide. For Mo, the formation of volatile $\mathrm{MoO}_{3}$ is also responsible for the low oxygen content in the NiCrMo coating. However, the severe post-deposition oxidation may close such in-flight deoxidizing effect since it was observed that a high deposition temperature results in high oxygen content in APS Mo coating (Ref 122). It has been known that with the Nibased self-fluxing alloys which contain deoxidizing elements such as B, Si and C, Kuroda's group reported a very interesting result that molten $\mathrm{NiCrBSiC}$ droplets with very low oxygen content can be generated by plasma spraying. It leads to a coating with substantially low oxygen contents in comparison with $\mathrm{Ni20Cr}$ coating (Ref 19). The low oxygen content of the coating was attributed to the deoxidizing effect of in-flight molten particles by deoxidizers such as $\mathrm{B}, \mathrm{Si}, \mathrm{C}$.

Thermodynamically, whether the oxidation of the specific element in a molten metal alloy consisting of multiple alloying elements occurs is determined by its Gibbs free energy of the oxide formation. The oxide formation energy of a metal element depends on temperature. 
At a higher temperature range than the melting points of iron and nickel, the oxide formation free energies of the elements such as B and Si becomes more negative than $\mathrm{Fe}$, $\mathrm{Ni}$ and main alloying elements as shown in Fig. 14. Thus, they are known as deoxidizers having a higher affinity for oxygen and have been utilized in the metallurgical industry for reducing oxides for refining (Ref 123). Such effect is also the primary theoretical base for producing oxide-free self-fluxing alloy coating with metallurgical bonding to the substrates. When metal spray particles are heated to a molten state, therefore, it is thermodynamically possible for iron, nickel, cobalt, and copper-based alloys and their main alloy elements to be protected from oxidation by boron or silicon. However, when this effect was applied to iron base materials by adding B or Si by Zeng et al., although it is effective to reduce the oxide inclusions, the experiment yielded a little discouraging result by showing that the oxygen content in the coatings increased with the increase of the spray distance (Ref 20). This fact implied that the deoxidizing effect could not completely avoid the oxidation of the in-flight particles. The possible reason is that spray particles were not heated to sufficiently high temperature as mentioned later. If the deoxidizing effect works throughout the whole in-flight process, the oxygen content in the coating should depend only on the post-spray oxidation and consequently decrease with the increase of the spray distance. This is because the heating effect of high temperature plasma jet on the deposited coating is gradually decreased with increasing spray distance, and thus, the post-deposition oxidation degree will be decreased with increasing spray distance.

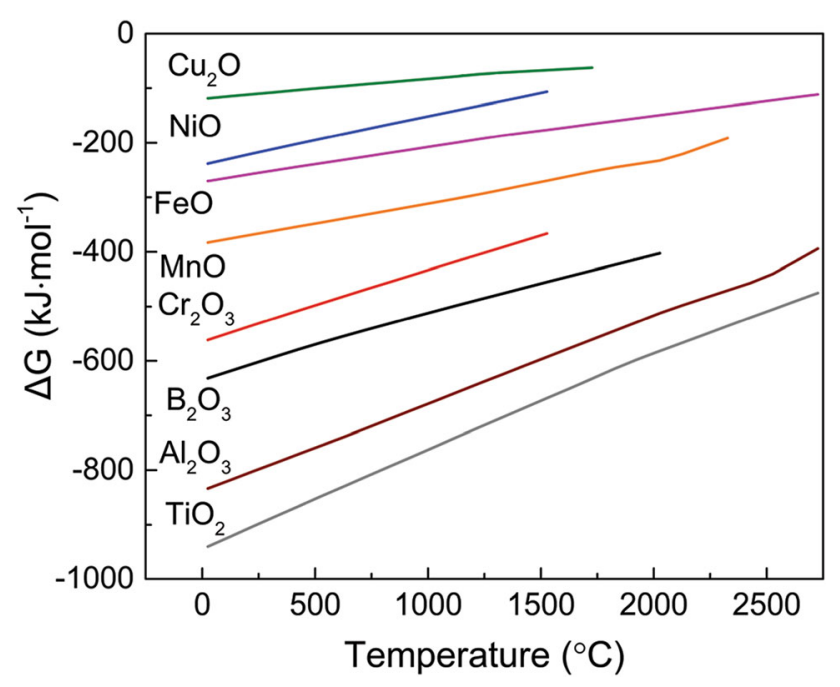

Fig. 14 Change of Gibbs free energy for the oxide formation of typical different metal elements with the temperature (Ref 46)

\section{Kinetic Requirements for In-Flight De-Oxidizing of Spray Molten Droplets}

During all those traditional metallurgical applications such as the post-spray fusing treatment of self-fluxing alloy coatings, the resultant oxides from the oxidation of deoxidizers appear in molten liquid or solid as protective slag. Fortunately, simultaneous use of boron and silicon in selffluxing alloys allows the formation of boron silicates with a low melting point, density and viscosity to benefit its float out of molten alloy and avoid inclusions inside the alloys. However, to achieve oxide-free molten alloy droplets during thermal spraying in the ambient atmosphere, the resultant oxides must be completely evaporated. Accordingly, the kinetics of de-oxidation and continuous rapid removal are essential to achieve oxide-free molten metal droplets in ambient atmosphere.

Recently, a strategy to generate oxide-free molten droplets in the ambient atmosphere was proposed by designing metallic powders containing deoxidizer elements and also generating ultra-high temperature droplets (Ref 46, 124, 125). Following this strategy, three necessary conditions must be fulfilled to generate oxide-free molten metal droplets in an open ambient atmosphere. (I) The powders should have the deoxidizer elements such as boron or carbon as well. (II) The molten metal particles should have enough high temperature. Although the deoxidizer has a higher affinity with oxygen than metallic elements such as $\mathrm{Fe}, \mathrm{Ni}, \mathrm{Co}, \mathrm{Cu}, \mathrm{Cr}$ and it is preferentially oxidized to prevent all other elements from oxidation, the formed boron oxide may be included in the coating. Therefore, the droplet should have an adequately high temperature to instantly evaporate the oxide resulting from oxidation of deoxidizers. For the alloys containing boron, when the molten droplet is heated to a temperature higher than the boiling point of boron oxide $\left(1860{ }^{\circ} \mathrm{C}\right)$, the deoxidizing becomes very effective since the resultant boron oxide can be removed by instant evaporation. (III) The deoxidization and subsequently instant evaporation of resulting oxide must take place throughout the in-flight region. This requires rapid mass transfer of the boron deoxidizer from its inside to the droplet surface. Among the above three requirements, the first one is concerned with the thermodynamic design of the powder which endows the spray powders with the possibility of in-flight deoxidizing effect. The other two requirements are concerned with the oxidation kinetics of the deoxidizer elements and evaporation kinetics of the resultant oxides, and transport kinetics of deoxidizing elements to the droplet surface to maintain the continuous deoxidizing.

Dong et al. showed that through modification to the conventional nozzle of plasma torch with an internal powder inject, the NiCrBSi powders were heated to a 
temperature higher than $2200{ }^{\circ} \mathrm{C}$ in a spray distance range from 60 to $200 \mathrm{~mm}$ (Ref 45). Such high temperature ensures rapid evaporation of deoxidizing resultant oxides including $\mathrm{B}_{2} \mathrm{O}_{3}$ and $\mathrm{SiO}_{2}$. A similar result was also confirmed for plasma spraying of Ni20Cr4B powder particles (Ref 46). Therefore, it was demonstrated that the temperature requirement for rapid evaporation of the oxides from the deoxidizer elements B and Si can be fulfilled through the design of the plasma torch.

Since oxidation occurs from the surface of a molten droplet during in-flight, the consumption of deoxidizer by continuous oxidation may lead to a decrease of the deoxidizer element content in the molten droplet (Ref $19,20,46)$. Such selective oxidation results in a deficiency or depletion of the deoxidizer elements near the droplet surface region. Thus, the oxidation of other alloying elements may occur. To avoid such case and maintain the continuous deoxidizing throughout in-flight of the molten metal droplet, rapid transfer of the deoxidizer element from the inner of molten droplet toward its surface is necessary. The selective oxidation of deoxidizer elements within spray molten droplets is kinetically similar to preferential element vaporization loss observed for plasma spraying of multiple constituent ceramics (Ref 126-130). The previous investigations showed that two types of mass transfer mechanisms are involved in the movement of elements within molten spray droplets: diffusion and convection (Ref 128, 131). The diffusion is a slow-rated mass transfer process that hinders the selectively preferential loss of element during plasma spraying. On the other hand, convection mass transfer is a rapid mass transfer process that promotes selectively preferential evaporation loss. To promote the rapid convection mass transfer, Hill's vortex needs to be developed within a molten droplet. The reduction of spray particle size is effective to promote Hill's vortex convection flow within a molten droplet (Ref 132). The heating of spray particles to a highly over-heated state with significantly reduced viscosity and surface tension also benefits the development of Hill's vortex flow. Thus, the high temperature required for rapid evaporation of oxide of the deoxidizer benefits the kinetics of mass transfer of in-flight molten droplets.

\section{In-Situ In-Flight Deoxidizing of Molten Spray Metal Droplets in Open Atmosphere}

Using boron added alloys including Ni22Cu14Cr (Ref 124), Cu30Ni (Ref 125), Ni20Cr (Ref 46), the generation of oxide-free molten droplets by in-situ in-flight deoxidizing effects were well confirmed. Figure 15 shows the effect of the spray distance on the oxygen content in the APS sprayed NiCuCr coatings under two different substrate cooling conditions by molten droplets of a temperature higher than $2000{ }^{\circ} \mathrm{C}$ (Ref 124). The oxygen content in the coatings decreases with the increase of the spray distance. This reveals that the in-flight oxidation of alloying elements is completely suppressed and the oxygen inclusion is only conducted by the post-deposition oxidation mechanism. Figure 16 shows the oxygen contents of several coatings deposited using the powders with different deoxidizers in comparison with conventional $\mathrm{Ni} 20 \mathrm{Cr}$ coatings with the molten droplets having a temperature higher than $2200{ }^{\circ} \mathrm{C}$, while flame-sprayed Ni20Cr4B coatings were plotted for comparison. The temperatures of spray particles during APS and flame spraying are shown in

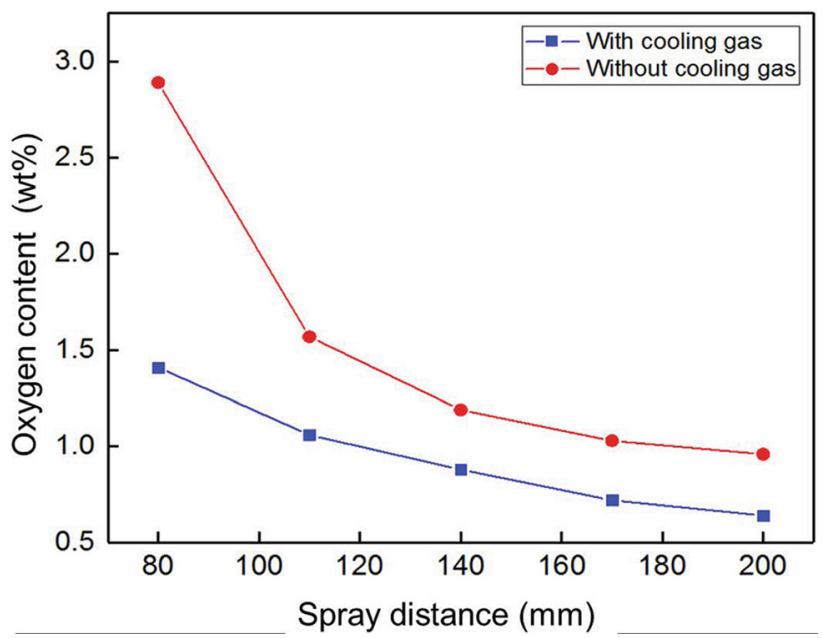

Fig. 15 Change of the oxygen content in atmospheric plasmasprayed $\mathrm{NiCuCrB}$ coatings with the spray distance. The coatings were deposited both with/without substrate cooling from its back of sample by air jet for comparison showing that the oxygen content in the coating depends on the post-deposition oxidation. (Ref 124)

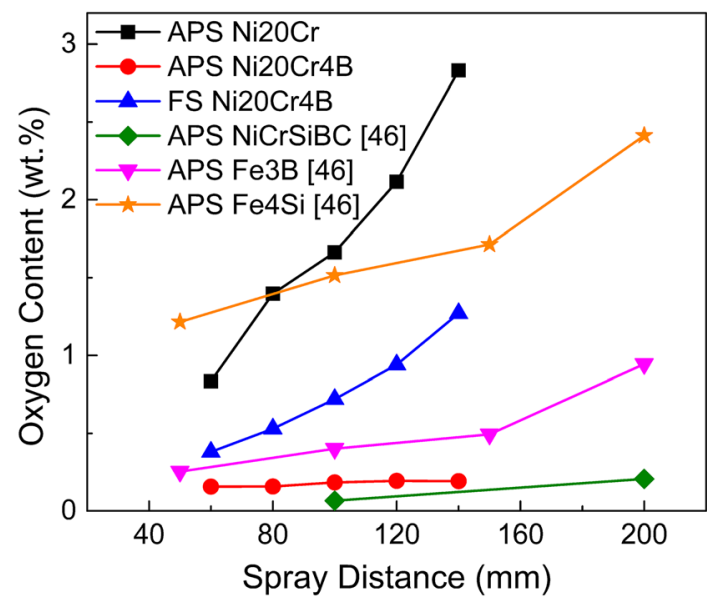

Fig. 16 Comparison of the dependency of the oxygen contents on spray distance for different metal coatings by APS and flame spraying with different powders for comparison. During flame spraying the temperature of molten spray particles is lower than plasma spraying (Refer to Fig. 17 reported by Dong et al.) (Ref 46) 
Fig. 17 (Ref 46). For the Ni20Cr coating, its oxygen content presents an increasing trend with increasing spray distance which is consistent with the theoretical trend and experimental results reported (Ref 112-116). Through adding boron to $\mathrm{Ni20Cr}$ powder, the oxygen content in the coating is significantly reduced. Furthermore, the oxygen content in the Ni20Cr-4B coating is maintained at a low level of about $0.18 \mathrm{wt} . \%$ despite a change of spray distance. It was found that the post-deposition oxidation-induced oxygen content in the HVOF NiCrAlY coatings showed little dependency on spray particle size while the in-flight oxidation resultant oxygen content increased exponentially with decreasing spray particle size (Ref 111). Therefore, the dependency of the oxygen content in the APS NiCrB coating on the spray distance reveals that only very limited oxide was formed through the post-deposition oxidation in the open atmosphere in comparison with a remarkable increase of oxygen content in the conventional $\mathrm{Ni20Cr}$ coating with increasing spray distance. On the other hand, when the same spray powders were used for flame spraying under the conditions that the droplet temperature is lower than $1860{ }^{\circ} \mathrm{C}(\operatorname{Ref} 46)$, the oxygen content in the coating increases significantly with the spray distance (Fig. 16). This can be attributed to slow deoxidizing kinetics which resulted in the increase of oxygen content in the deposit with the increase of the spray distance. This trend is similar to that observed for the coatings without any deoxidizer element. Moreover, the trend is similar to that of the $\mathrm{Fe} 3 \mathrm{~B}$ and $\mathrm{Fe} 4 \mathrm{Si}$ coatings reported by Zeng et al. (Ref 19, 20), suggesting that the complete deoxidizing throughout in-flight requires the molten droplets to be maintained at sufficiently high temperature over the whole spray distance.

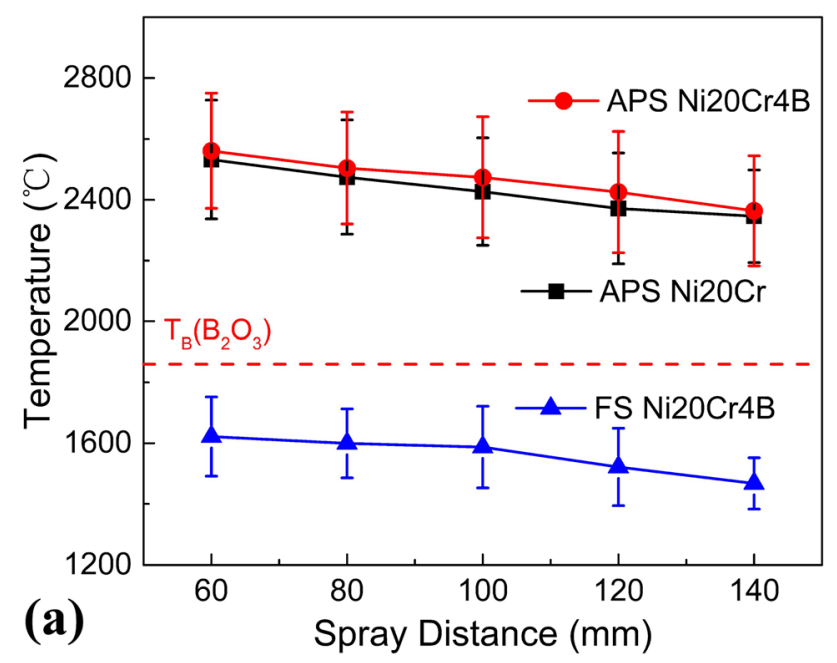

Fig. 17 Change of molten Ni20Cr4B and Ni20Cr spray particles against spray distance during APS and flame spraying (Ref 46)
With Al-containing alloy, carbon instead of B should be used as the deoxidizer with the requirement to have molten droplets heated to a temperature higher than $2000{ }^{\circ} \mathrm{C}$. As diamond particles are added into ball-milled $\mathrm{Ni}-\mathrm{Al}$ composite powder as a deoxidizer, a NiAl compound coating with an oxygen content of $0.61 \mathrm{wt} . \%$ was deposited with molten droplets of a temperature higher than $2100{ }^{\circ} \mathrm{C}$ (Ref 133). This is remarkably lower than $3.23 \mathrm{wt} . \%$ for $\mathrm{NiAl}$ coating deposited using Ni-Al composite powders (Ref 134) and oxide contents in NiAl coatings reported by Deshpande et al (Ref 87). Figure 18 illustrates a typical microstructure of NiAl coating with a low oxygen content by APS. The tiny oxides were attributed to smaller droplets. Therefore, the in-situ deoxidizing effect during inflight molten metal droplet is realized through powder composition design and particle heating control. It should be pointed out that only using plasma spraying the droplet temperature requirement can be possibly fulfilled with insitu in-flight deoxidizing.

As it has been pointed out that the generation of oxidefree molten droplets throughout its traveling requires three necessary conditions ( $\operatorname{Ref} 46$ ). The first condition is to use the powder having deoxidizer elements that have a higher affinity to oxygen than all other alloying elements in the powder. The second condition is to heat metal spray molten droplets to a temperature to evaporate instantaneously the deoxidizing resultant oxides. This means that the droplet temperature should be higher than the boiling point of the oxides. The third condition is to have sufficient deoxidizers on the surface region of molten droplets for continuous protection of alloy elements from oxidation by rapid mass transfer from spray particles through convective circulation. This makes in-flight droplets maintain adequate deoxidizer content on their surface. Due to the rapid consumption of deoxidizing elements by oxidation a

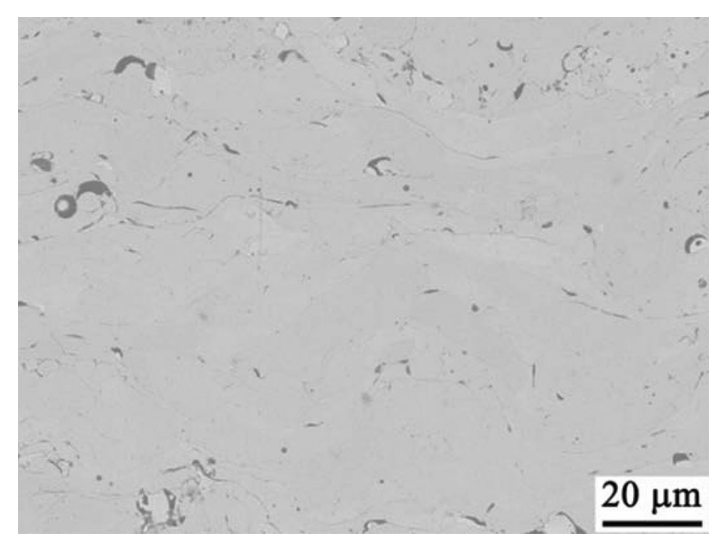

Fig. 18 Typical cross-sectional microstructure of atmospheric plasma-sprayed NiAl intermetallic compound coating using ballmilled Ni-Al composite powders with addition of diamond particles as deoxidizer (Ref 133) 
deoxidizer deficient layer appears near the droplet surface. This layer limits the supply of deoxidizer when only diffusion mechanism works within the droplet and makes the oxidation of the in-flight particle not completely suppressed. To ensure enough deoxidizer supply, a rapid mass transfer mechanism like convection flow within molten metal droplets is required. Namely, to enable convective flow mass transfer the Hill's spherical vortex flow inside the droplet is required. Zhang et al. reported that with the oxidation of iron droplet the Hill's spherical vortex rapidly sweeps away the oxide on the surface into the inner (Ref 132). Thus, with such convection flow, the compositions within molten droplets are rapidly averaged to avoid the formation of a surface layer with deoxidizer depletion. As pointed out by Zhang et al., the intensity of Hill's vortex becomes lower when the size of a molten particle is larger owing to a lower temperature and higher viscosity of larger particles. Such size effect on oxide preferential vaporization loss is consistent with that observed for plasma spraying of multicomponent ceramic particles (Ref 126131). Those facts suggest that to maintain continuous insitu deoxidizing to achieve oxide-free metal droplets it is necessary to use optimized molten spray particles parameters including the use of small sized powder particles if the preferential evaporation induced chemical composition change is acceptable. This is because the evaporation loss of spray particles increases with the decrease of spray particle size (Ref 135).

\section{Strategy for Depositing Bulk-Like Metal Coatings Through Spread-fusing Self-Bonding Mechanism with In-Situ Deoxidizing Effect by APS}

The self-fluxing alloys are used to produce bulk-like coating through the spray-fusing process. The common feature of the alloys contains certain amount of boron, silicon and carbon as well. Through eutectic phase formation of alloy elements with boron to lower the melting point of alloys by approximately $300{ }^{\circ} \mathrm{C}$, it makes it possible to fuse the entire coating but keep Fe-based or Nibased substrate at a solid state. These elements act also as reducing agents to react with oxygen in the surrounding atmosphere and reduce oxides in the alloy coating and substrate surface as well, enhancing the wettability of the alloys with the substrate during fusing. Due to its low density, low viscosity and low melting point, the resultant boron silicate floats out molten alloy layer and covers on fused alloy surface, preventing alloy from oxidation. Thus, a fully dense alloy coating metallurgically bonded to a substrate is produced by the spray-fusing process. With the addition of chromium, improved corrosion resistance can be achieved. Meanwhile, by tailoring the amount of carbides, borides and silicides in the coating, the coating hardness can be changed from $20 \mathrm{HRC}$ even up to $60 \mathrm{HRC}$ to meet different wear application requirements (Ref 29). It is a well-established process and documented in many books (Ref 1). It was noticed by Zeng et al. (Ref 19) that the fluxing elements in self-fluxing alloys can be utilized as deoxidizers to reduce the oxides in in-flight $\mathrm{NiCrBSiC}$ molten droplets during plasma spraying. Thus, the NiCrBSiC coating with remarkably low oxygen content was deposited in comparison with $\mathrm{Ni20Cr}$ coating plasmasprayed at the same spray conditions (Ref 19), this is because Ni-based self-fluxing alloys are typical spray materials containing de-oxidizers.

Therefore, the alloys containing the deoxidizer elements such as self-fluxing alloys can be utilized to achieve oxidefree molten droplets for depositing a bulk-like metal coatings by APS. However, when plasma spraying of metal coatings is carried out in an open atmosphere, the postdeposition oxidation is still not suppressed. In particular, since the coatings are generally deposited through multiple of passes, the coating surface of individual passes at a high temperature is exposed to ambient atmosphere much long. It is inevitable that the coating surface of interpasses is oxidized and subsequently covered by a thin layer of oxide scale. To achieve a metallurgical bonding throughout splat interfaces including these interpass interfaces the spreadfusing mechanism must be developed during spreading of impacting molten metallic droplets. Since the melting point of common Ni-based alloys is near $1400{ }^{\circ} \mathrm{C}$, this requires molten droplets of a temperature higher than $2400{ }^{\circ} \mathrm{C}$ to create the spread-fusing self-bonding effect (Ref 45$)$. On the other hand, with the addition of alloying element $\mathrm{B}$, the melting point of the alloys is reduced. For Ni-based selffluxing alloys, their melting points can be lowered to about $100{ }^{\circ} \mathrm{C}$. This low melting point promotes easy initiation of the spread-fusing self-bonding since the necessary minimum droplet temperature for developing the spread-fusing self-bonding is reduced to about $1800{ }^{\circ} \mathrm{C}$. Using a special designed anode nozzle for effective heating, Dong et al. demonstrated that a stream of the molten droplets of a temperature higher than $2200{ }^{\circ} \mathrm{C}$ can be achieved (Ref 45 , 46), which meets the requirement for initiation of spread-fusing mechanism. At such high temperature, the deoxidizing mechanism works well to generate oxide-free molten NiCrBSi droplets throughout whole the in-flight in ambient atmosphere. Thus, since all requirements are fulfilled, the coating with few oxide inclusions and sufficiently metallurgical bonding at splat interfaces is deposited in open ambient atmosphere. Figure 19 shows a typical microstructure of plasma-sprayed NiCrBSi coating. Apparently, it is remarkably dense. The etching test of cross section of the coating, from which the unbonded splat interfaces can be usually visualized, further confirmed that 
the fully dense coating is deposited by sufficiently bonded lamellae.

The abrasive wear against emery paper was conducted under different applied loads to examine the abrasive wear behavior of the coating. For thermal spray coating with lamellar structure, the wear behavior at low stress can be much different from that at high stress. This is because the wear mechanism transition from bulk-like uniform wear to lamella spalling accelerated wear occurs as observed for other types of coatings such as HVOF metal coatings (Ref 24) and WC-Co coatings (Ref 13). Therefore, the wear performance of HVOF WC-Co coating is lower than that of sintered bulk (Ref 13). Compared to the flame-sprayed lamellar-structured $\mathrm{NiCrBSi}$ coating that presents a

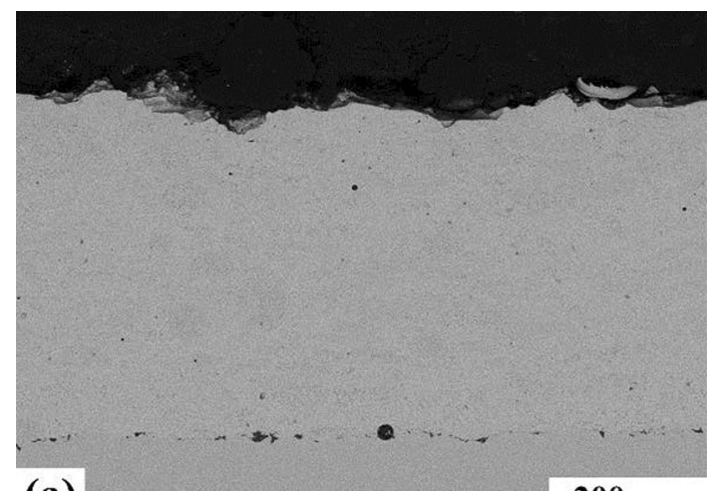

(a) $200 \mu \mathrm{m}$

Fig. 19 Microstructure of the as-plasma-sprayed NiCrBSi coating with little trace of lamellar structure (Ref 45)

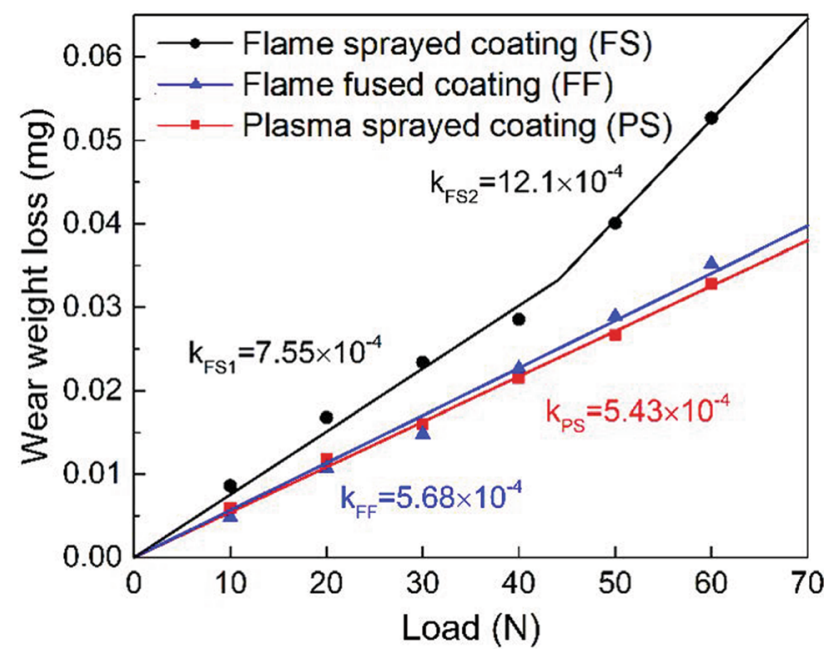

Fig. 20 Comparison of load-dependence of the abrasive wear weight loss of the as-plasma-sprayed NiCrBSi coating with those of as-flamesprayed $\mathrm{NiCrBSi}$ and flame-spray-fused $\mathrm{NiCrBSi}$ coating. A critical load for the as-flame-sprayed coating is presented over which the accelerated wear occurs through lamella-peeling dominant mechanism. The APS NiCrBSi presented the same abrasive wear behavior as that of spray-fused bulk NiCrBSi (Ref 45) significant loading dependency of wear mechanisms (Fig. 20), the plasma-sprayed NiCrBSi coating reveals the same linear wear behavior as that of the spray-fused coating. This fact indicates that the mechanical behavior of the plasma-sprayed NiCrBSi coating with the spread-fusing mechanism is comparable to the spray-fused coating. Moreover, this result also means that the lamellae in the plasma-sprayed NiCrBSi coating are sufficiently bonded together with each other to behave bulk-like. However, when the spread-fusing mechanism is not developed through heating control of spray particles, plasma-sprayed NiCrBSi coating still presents a conventional lamellar structure. The abrasive wear test of such coating yielded a much higher abrasive wear rate even by a factor of three than those of spray-fused bulk-like NiCrBSi (Ref 12).

The investigation into the electrochemical behavior also revealed that the APS dense NiCrBSi coating presents comparable behavior with that of spray-fused coating in terms of both the open circuit potential and the dynamic polarization (Fig. 21) (Ref 45). Similar results were also acquired using boron-alloyed Ni20Cr alloy coating (Ref 46). As a result, it is clear that through materials design to control their physical properties along with the control of overheating temperature of spray molten droplets, bulk-like metal coatings of the same mechanical and electrochemical performance as the bulk counterparts can be simply deposited by plasma spraying in an open ambient atmosphere.

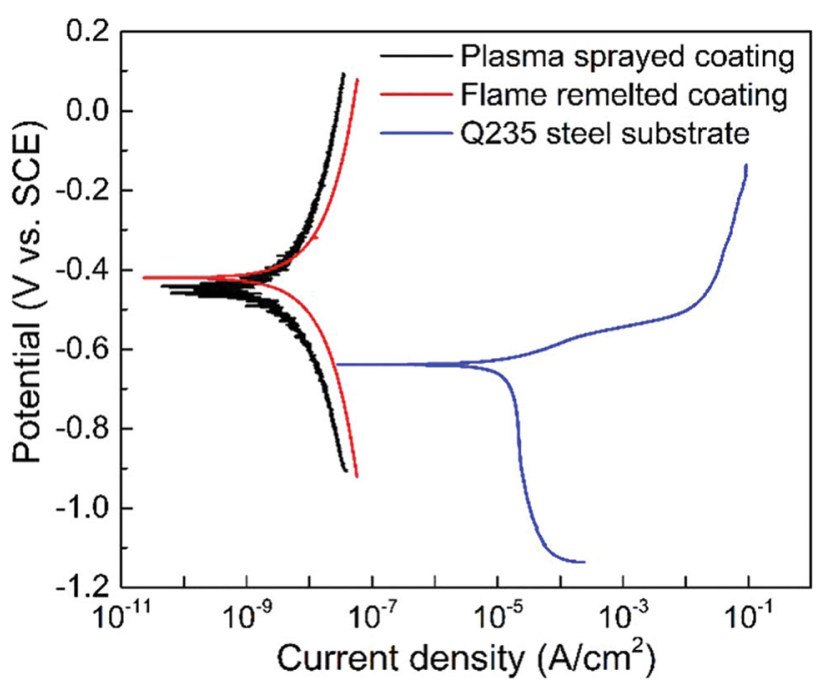

Fig. 21 Comparison of the dynamic polarization behavior of plasmasprayed NiCrBSi coating on Q235 with those of the flame spray-fused NiCrBSi on Q235 steel and bare Q235 steel substrate in $3.5 \% \mathrm{NaCl}$ suggesting little trace of solution penetration during the electrochemical test and that the coating behaviors electrochemically in the same way like bulk-NiCrBSi (Ref 45) 


\section{Conclusions and Prospective}

Depositing thermal spray metallic coatings with bulk-like microstructure is the most effective way to tape out the full potential of metal coating materials for corrosion and wear protection. This requires sufficiently metallurgical bonding between splat interfaces. Using vacuum plasma spraying in a reduced inert atmosphere, bulk-like metal coatings can be deposited by increasing deposition temperature using preheating substrate. However, under an ambient atmosphere, the oxidation of substrate and previously deposited coating layer hinders the applicability of the strategy to increase deposition temperature. Instead, the spread-fusing selfbonding mechanism can be proposed for producing bulklike thermal spray metallic coatings. To realize such a selfbonding mechanism, ultra high-temperature molten metal droplets free of oxide need to be generated. The minimum droplet temperature for the self-bonding can be estimated by one-dimensional heat transfer model. Thus, the first challenge is to generate ultra-high temperature droplets. For Fe-based and Ni-based coatings, Mo-cladded powder design was proposed to create ultra-high temperature droplets, which can fulfill the requirements for spread-fusing self-bonding. Using shrouded plasma spraying, dense bulklike Ni-based alloy coatings with limited oxides and sufficient lamellar bonding can be deposited, and the coatings present the same mechanical behavior as that of casted IN738 bulk. The fully dense coating for complete protection of metal from corrosion can also be fabricated.

A second challenge is to generate oxide-free molten metal droplets in an open ambient atmosphere. It was shown that three conditions need to be fulfilled. (I) The powders should be designed to have self-deoxidizing potential with a certain amount of deoxidizing alloying elements (B, C, etc.). (II) Ultra-high temperature droplets should be generated to achieve rapid evaporation of the oxides formed by deoxidizing and spread-fusing selfbonding mechanism. It was clearly shown that the generation of molten metal droplets of a temperature higher than $1860{ }^{\circ} \mathrm{C}$ leads to the formation of oxide-free Cu-based, oxide-free Ni-based alloy molten droplets containing deoxidizer boron. For $\mathrm{Cu}$-based and Ni-based alloys, the addition of a de-oxidizer such as $\mathrm{B}$ can also decrease the melting point of the alloys. This not only makes the droplet temperature requirement be easily fulfilled for self-bonding, but also provides the alloy droplets with an in-situ inflight deoxidizing effect, by which oxide-free metal droplets can be generated in open ambient atmosphere. Consequently, the deposition of bulk-like dense metal coatings with sufficiently bonded lamellae is realized by APS.

Although the recent research progresses emphasize the possibility to deposit the bulk-like dense metallic coatings with fully metallurgical intersplat bonding, many fundamental research works are still required to well understand the concerned physical and chemical phenomena. The main topics can be raised as follows. (I) How to effectively heat metal powder particles to the temperature near boiling point of the main alloying elements is the first challenge for the application of the present strategies for different applications by APS. This involves the control and enhancement of heat transfer between spray metal particles and high temperature flame, although it is supposed that the physical phenomena behind heat transfer have been well understood. (II) Rapid mass transfer through Hill's vortex flow mechanism within in-flight molten droplet is required to maintain the continuously sufficient supplying of deoxidizer elements to the molten droplet surface from its inner to acquire oxide-free molten metal droplets along the whole spray distance range in an open air. (III) The physical absorption phenomenon of gas species by molten droplets at the ultra-hot state needs to be clarified since the gas species solubility in molten droplets increases with the droplet temperature and absorbed gas species may not be released during rapid spreading process. (IV) How the wetting of spreading melt at a high temperature to the underlying splat surface contributes to the formation of metallurgical bonding between adjacent splats within one spray pass is an important topic since with spreading of molten melt the temperature of melt at the spreading front may decrease significantly. Once a tiny fraction of the interface at the periphery of the splat is not bonded effectively, the corrosive media in a liquid or gas state could penetrate through the coating and cause corrosion at the substrate/coating interface. Thus, complete wetting throughout the whole splat interface during spreading is required. Accordingly, the modeling of the splat formation process to clarify the melt/substrate interface temperature evolution across the whole contact interface will help to understand such phenomena. (V) How the spreading melt makes self-adapting to a wavy splat surface profile to achieve the full intersplat metallurgical bonding is not taken into account yet but is important to be clarified. (VI) The control approaches for the coating surface oxidation between each scanning spray pass should be developed to avoid the serious effect on the bonding formation and how their effect on the bonding formation affects the performance of the coatings may challenge the successful application of the present strategies. (VII) The deposition of the metallic coatings by ultra-hot droplets for sufficiently bonded lamellae may change the residual stress distribution in the coating. How the residual stress evolves and affects the coating performance would also need to be clarified. 
Acknowledgments The present project is financially supported by National Natural Science Foundations (Grant No. U1837201, 52031010) and National Science and Technology Major Project (2019-VII-0007-0147).

\section{References}

1. P. Fauchais, J.V.R. Heberlain, and M.I. Boulos, Thermal Spray Fundamentals from Powder to Part, Springer, New York, 2014.

2. J.R. Davis, Handbook of Thermal Spray Technology, ASM International, Materials Park, Netherland, 2004.

3. A. Vardelle, C. Moreau, J. Akedo et al., The 2016 Thermal Spray Roadmap, J. Therm. Spray Technol., 2016, 25(8), p 13761440.

4. C.C. Berndt and R. McPherson, The adhesion of plasma sprayed ceramic coatings to metals, Materials Science Research Surfaces and Interfaces in Ceramic and Ceramic-Metal Systems, Vol 14, J. Pask, A. Evans Ed., Plenum Press, New York and London, 1980, p 619-628

5. R.C. Tucker, Structure Property Relationships in Deposits Produced by Plasma Spray and Detonation Gun Techniques, J. Vac. Sci. Technol., 1974, 11(4), p 725-734.

6. V.V. Sobolev, J.M. Guilemany, J. Nutting, and J.R. Miquel, Development of Substrate-Coating Adhesion in Thermal Spraying, Int. Mater. Rev., 1997, 42(3), p 117-136.

7. R. McPherson and B.V. Shafer, Interlamellar Contact within Plasma Sprayed Coatings, Thin Solid Films, 1982, 97, p 201204.

8. C.-J. Li and A. Ohmori, Relationship Between the Structure and Properties of Thermally Sprayed Deposits, J. Therm. Spray Technol., 2002, 11(3), p 365-374.

9. R. McPherson, A Model for the Thermal Conductivity of Plasma Sprayed Ceramic Coatings, Thin Solid Films, 1984, 112, p 8995.

10. A. Ohmori and C.-J. Li, Quantitative Characterization of the Structure of Plasma Sprayed A12O3 Coating by Using Copper Electroplating, Thin Solid Films, 1991, 201, p 241-252.

11. S. Kuroda and T.W. Clyne, The Quenching Stress in Thermally Sprayed Coatings, Thin Solid Films, 1991, 200, p 49-66.

12. J. Rodriguez, A. Martin, R. Fernandez, and J.E. Fernandez, An Experimental Study of the Wear Performance of NiCrBSi Thermal Spray Coatings, Wear, 2003, 255, p 950-955.

13. D.A. Stewart, P.H. Shipway, and D.G. McCartney, Abrasive Wear Behaviour of Conventional and Nanocomposite HVOFSprayed WC-Co Coatings, Wear, 1999, 225-229, p 789-798.

14. C.U. Hardwicke and Y.-C. Lau, Advances in Thermal Spray Coatings for Gas Turbines and Energy Generation: A Review, $J$. Therm. Spray Technol., 2013, 22, p 564-576.

15. Y. Liu, J. Huang, X.H. Feng, and H. Li, Thermal-Sprayed Photocatalytic Coating for Biocidal Applications: A Review, $J$. Therm. Spray Technol, 2021, 30, p 1-24.

16. J.A. Gan and C.C. Berndt, Review on the Oxidation of Metallic Thermal Sprayed Coatings: A Case Study with Reference to Rare-Earth Permanent Magnetic Coatings, J. Therm. Spray Technol., 2013, 22, p 1069-1091.

17. S.E. Hartfifield-Wunsch and S.C. Tung, The effect of microstructure on the wear behavior of thermal spray coatings, Thermal Spray Industrial Applications. C.C. Berndt, S. Sampath Ed., ASM International, Materials Park, Netheland, 1994, p 1924

18. K. Dobler, H. Kreye, and R. Schwetzke, Oxidation of Stainless Steel in the High Velocity Oxy-Fuel Process, J. Therm. Spray Technol., 2000, 9(3), p 407-413.
19. Z. Zeng, S. Kuroda, and H. Era, Comparison of Oxidation Behavior of Ni-20Cr Alloy and Ni-base Self-fluxing Alloy During Air Plasma Apraying, Surf. Coat. Technol., 2009, 204, p 69-77.

20. Z. Zeng, S. Kuroda, J. Kawakita, M. Komatsu, and H. Era, Effects of Some Light Alloying Elements on the Oxidation Behavior of $\mathrm{Fe}$ and Ni-Cr Based Alloys During Air Plasma Spraying, J. Therm. Spray Technol., 2010, 19, p 128-136. https://doi.org/10.1007/s11666-009-9447-6

21. P. Fauchais, M. Vardelle, A. Vardelle, and J.F. Coudert, Plasma Spraying of Ceramic Particles in Argon-Hydrogen D.C. Plasma Jets: Modeling and Measurements of Particles in Flight Correlation with Thermophysical Properties of Sprayed Layer, Metall. Trans. B, 1989, 20B, p 263-276.

22. Y.P. Wan, J.R. Fincke, and S. Sampath, Modeling and Experimental Observation of Evaporation from Oxidizing Molybdenum Particles Entrained in a Thermal Plasma Jet, Int. J. Heat Mass Transf., 2002, 45, p 1007-1015.

23. C.-J. Li and J.-L. Li, Transient Contact Pressure during Flattening of Thermal Spray Droplet and its Effect on Splat Formation, J. Therm. Spray Technol., 2004, 13(2), p 229-238.

24. P. Sassatelli, G. Bolelli, L. Lusvarghi, T. Manfredini, and R. Rigon, Manufacturing and Properties of High-Velocity Oxygen Fuel (HVOF)-Sprayed FeVCrC Coatings, J. Therm. Spray Technol., 2016, 25(7), p 1302-1321. https://doi.org/10.1007/ s11666-016-0451-3

25. P. Sassatelli, G. Bolelli, M.L. Gualtieri, E. Heinonen, M. Honkanen, L. Lusvarghi, T. Manfredini, R. Rigon, and M. Vippola, Properties of HVOF-Sprayed Stellite-6 Coatings, Surf. Coat. Technol., 2018, 335, p 45-62. https://doi.org/10.1016/j. surfcoat.2018.01.078

26. S.A. Galedari, A. Mahdavi, F. Azarmi, Y. Huang, and A. McDonald, A Comprehensive Review of Corrosion Resistance of Thermally-Sprayed and Thermally-Diffused Protective Coatings on Steel Structures, J. Therm. Spray Technol., 2019, 28, p 645-677.

27. R. Ahmed, O. Ali, C.C. Berndt, and A. Fardan, Sliding Wear of Conventional and Suspesion Sprayed Nanocomposite WC-Co Coatings: An invited review, J. Therm. Spray Technol., 2021, 30, p 800-861.

28. M. Hauer, F. Gartner, S. Krebs, T. Klassen, M. Watanabe, S. Kuroda, W. Krommer, and K.-M. Henke, Process Selection for the Fabrication of Cavitation Erosion Resistant Bronze Coatings by Thermal and Kinetic Spraying in Maritime Applications, $J$. Therm. Spray Technol., 2021, 30, p 1310-1328.

29. H. Hiraga, T. Inoue, H. Shimura, and A. Matsunawa, Cavitation Erosion Mechanism of NiTi Coatings Made by Laser Plasma Hybrid Spraying, Wear, 1999, 231, p 272-278.

30. H. Hiraga, T. Inoue, S. Kamado, Y. Kojima, A. Matsunawa, and H. Shimura, Fabrication of NiTi Intermetallic Compound Coating Made by Laser Plasma Hybrid Spraying of Mechanically Alloyed Powders, Surf. Coat. Technol., 2001, 139, p 93100.

31. K. Simunovic, S. Havrlisan, T. Saric, and D. Vukelic, Modeling and Optimization in Investigating Thermally Sprayed Ni-Based Self-Fluxing Alloy Coatings: A Review, Mater., 2020, 13, p 4584.

32. R. Rottger, S. Weber, W. Theisen, B. Rajasekeran, and R. Vassen, Mechanical Properties of Thermally Sprayed Fe Based Coatings, Mater. Sci. Technol., 2011, 27(6), p 973982.

33. J. Fiebig, E. Bakan, T. Kalfhaus, G. Mauer, and R. Vassen, Thermal Spray Processes for the Repair of Gas Turbine Components, Adv. Eng. Mater., 2020, 22, p 19011237.

34. D. Naumenko, R. Pillai, A. Chyrkin, and W.J. Quadakkers, Overview on Recent Developments of Bondcoats for Plasma 
Sprayed Thermal Barrier Coatings, J. Therm. Spray Technol., 2017, 26, p 1743-1757.

35. G.-H. Meng, B.-Y. Zhang, H. Liu, G.-J. Yang, T. Xu, C.-X. Li, and C.-J. Li, Highly Oxidation Resistant and Cost Effective MCrAlY Bond Coats Prepared by Controlled Atmosphere Heat Treatment, Surf. Coat. Technol., 2018, 347, p 54-65.

36. L. Pawlowski, Technology of Thermally Sprayed Anilox Rolls: State of Art, Problems, and Perspectives, J. Therm. Spray Technol., 1996, 5, p 317-334.

37. L. Pawlowski, Thick Laser Coatings: A Review, J. Therm. Spray Technol., 1999, 8(2), p 279-295.

38. D. Garcia-Alonso, N. Serres, C. Demian, S. Costil, C. Langlade, and C. Coddet, Pre-/During-/Post-Laser Processes to Enhance the Adhesion and Mechanical Properties of Thermal-Sprayed Coatings with a Reduced Environmental Impact, J. Therm. Spray Technol., 2011, 20, p 719-735.

39. J. Singh, B.N. Bhat, R. Poorman, A. Kar, and J. Mazumder, Laser Glazing of Vacuum Plasma Spray Coated NARloy-Z, Surf. Coat. Technol., 1996, 79(13), p 35-49.

40. N. Serres, F. Hlawka, S. Costil, C. Langlade, and F. Machi, Microstructures of Metallic NiCrBSi Coatings Manufactured via Hybrid Plasma Spray and In Situ Laser Remelting Process, $J$. Therm. Spray Technol., 2011, 20, p 336-343.

41. B. Arsenault, B. Champagne, D. Dube, P. Lambert, and C. Gelinas, Laser Processing of Plasma-Sprayed R-Ba-Cu-O Coatings, J. Therm. Spray Technol., 1993, 2(4), p 329-338.

42. H.L. Tsai and P.C. Tsai, Laser Glazing of Plasma-Sprayed Zirconia Coatings, J. Mater. Eng. Perform., 1998, 7(2), p 258264.

43. Z. Zhou, N. Eguchi, H. Shirasawa, and A. Ohmori, Microstructures and Characterization of Zirconia-Yttria Coatings Formed in Laser and Hybrid Spray Process, J. Therm. Spray Technol., 1999, 8(3), p 405-413.

44. J.-J. Tian, Y.-K. Wei, C.-X. Li, G.-J. Yang, and C.-J. Li, Effect of Post-spray Shot Peening Treatment on the Corrosion Behavior of NiCr-Mo Coating by Plasma Spraying of the ShellCore-Structured Powders, J. Therm. Spray Technol., 2018, 27, p 232-242. https://doi.org/10.1007/s11666-017-0659-x

45. X.-Y. Dong, X.-T. Luo, S.-L. Zhang, and C.-J. Li, A Novel Strategy for Depositing Dense Self-fluxing Alloy Coatings with Sufficiently Bonded Splats by One-Step Atmospheric Plasma Spraying, J. Therm. Spray Technol., 2020, 29(1), p 173-184. https://doi.org/10.1007/s11666-019-00943-4

46. X.-Y. Dong, X.-T. Luo, Y. Ge, and C.-J. Li, Enhancing the HotCorrosion Resistance of Atmospheric Plasma Sprayed Ni-Based Coatings by Adding a Deoxidizer, Mater. Des., 2021, 211, p 110145.

47. C.C. Berndt and C.K. Lin, Measurement of Adhesion for Thermally Sprayed Materials, J. Adh. Sci. Technol., 1993, 7(12), p 1235-1264.

48. J. Wang, X.-T. Luo, C.-J. Li, N. Ma, and M. Takahashi, Effect of Substrate Temperature on the Microstructure and Interface Bonding Formation of Plasma Sprayed Ni20Cr Splat, Surf. Coat. Technol., 2019, 371, p 36-46. https://doi.org/10.1016/j.surfcoat. 2019.01.085

49. Y. Zhang, S. Matthews, and M. Hyland, Understanding the Formation of Plasma-Sprayed Ni20Cr Splats Through Interface Observation, 2019, Appl. Surf. Sci., 2019, 469, p 691-702.

50. Y. Xia, C.H. Li, Y.W. Luan, X.J. Han, and J.G. Li, Molecular Dynamics Studies on the Correlation of Undercoolability and Thermophysical Properties of Liquid Ni-Al Alloys, Comput. Mater. Sci., 2016, 112, p 383-394.

51. P. Fauchais, M. Fukumoto, A. Vardelle, and M. Vardelle, Knowledge Concerning Splat Formation: An Invited Review, J. Therm. Spray Technol., 2004, 13(3), p 337-360.
52. C. Moreau, P. Cielo, and M. Lamontagne, Flattening and Solidification of Thermally Sprayed Particles, J. Therm. Spray Technol., 1992, 1, p 317-324.

53. A. McDonald, M. Lamontagne, S. Chandra, and C. Moreau, Photographing Impact of Plasma-Sprayed Particles on Metal Substrates, J. Therm. Spray Technol., 2006, 15, p 708-716.

54. S. Goutier, M. Vardelle, and P. Fauchais, Last Developments in Diagnostics to Follow Splats Formation during Plasma Spraying, J. Phys. Conf. Ser., 2011, 275, p 012003.

55. M.M. Schwartz, Brazing, 2nd ed. ASM International, Materials Park, OH USA, 2003.

56. X. Yin, Q. Ma, B. Cui, L. Zhang, X. Xue, S. Zhong, and D. Xu, Current Review On the Research Status of Cemented Carbide Brazing Filler Materials and Mechanical Properties, Met.s Mater. Int., 2021, 27, p 571-583.

57. B.N. Kocthkob and U.A. Shestelin, Plasma Spraying, Moskow Metallurgical Publishing, Japan-Soviet Communication Publishing Co. Ltd., Japan, 1978. (In Japanese).

58. L. Gyenis, A. Grimaud, O. Betoule, F. Monerie-Moulin, and P. Fauchais, Influence of temperature control during spraying on hardness and cohesion of alumina coating. In: S. Blum-Sandmeier, H. Eschnauer, P. Huber, A.R. Nicill (Ed.), Proceedings of 2nd Plasma-Technic-Symposium, Vol. 1 (Lucerne, Switzerland, June 5-7, 1991), p 95-101

59. V. Pershin, M. Lufitha, S. Chandra, and J. Mostaghimi, Effect of Substrate Temperature on Adhesion Strength of Plasma-Sprayed Nickel Coatings, J. Therm. Spray Technol., 2003, 12, p 370-376.

60. M. Fukumoto, I. Ohgitani, and T. Yasui, Effect of Substrate Surface Change on Flattening Behaviour of Thermal Sprayed Particles, Mater. Trans., 2004, 45(6), p 1869-1873.

61. A. Hasui, S. Kitahara, and T. Fukushima, On Relation between Properties of Coating and Spraying Angle in Plasma Jet Spraying, Trans. Natl. Res. Inst. Met., 1970, 12, p 9-20.

62. R.C. Dykhuizen, Review of Impact and Solidification of Molten Thermal Spray Droplets, J. Therm. Spray Technol., 1994, 13, p 351-361.

63. M. Fukumoto, S. Katoh, and I. Okane, Splat behavior of plasma sprayed particles on flat substrate surface, Thermal Spraying: Current Status and Future Trends. A. Ohmori Ed., Vol. 1, High Temperature Society of Japan, Osaka, Japan, 1995, p 353-358

64. C.-J. Li and J.-L. Li, Evaporated-Gas-Induced Splashing Model for Splat Formation during Plasma Spraying, Surf. Coat. Technol., 2004, 184(1), p 13-23.

65. A. McDonald, C. Moreau, and S. Chandra, Thermal Contact Resistance Between Plasma-Sprayed Particles and Flat Surfaces, Int. J. Heat Mass Transf., 2007, 50, p 1737-1749.

66. X. Jiang, Y. Wan, H. Herman, and S. Sampath, Role of Condensates and Adsorbates on Substrate Surface on Fragmentation of Impinging Molten Droplets during Thermal Spray, Thin Solid Films, 2001, 385, p 132-141.

67. H.B. Guo, R. Vassen, and D. Stover, Atmospheric Plasma Sprayed Thick Thermal Barrier Coatings with High Segmentation Crack Density, Surf. Coat. Technol., 2004, 2004(186), p 353-363.

68. S.-W. Yao, C.-J. Li, J.-J. Tian, G.-J. Yang, and C.-X. Li, Conditions and Mechanisms for the Bonding of a Molten Ceramic Droplet to a Substrate after High-speed Impact, ACTA Mater., 2016, 119, p 9-25.

69. L. Bianchi, A.C. Leger, M. Vardelle, A. Vardelle, and P. Fauchais, Splat Formation and Cooling of Plasma-Sprayed Zirconia, Thin Solid Films, 1997, 305, p 35-47.

70. J. Wang, C.-J. Li, G.-J. Yang, and C.-X. Li, Effect of Oxidation on the Bonding Formation of Plasma-sprayed Stainless Steel Splats onto Stainless Steel Substrate, J. Therm. Spray Technol., 2017, 26(1-2), p 47-59. 
71. A.A. Syeda, A. Denoirjeana, B. Hannoyerb, P. Fauchaisa, P. Denoirjeana, A.A. Khanc, and J.C. Labbe, Influence of Substrate Surface Conditions on the Plasma Sprayed Ceramic and Metallic Particles Flattening, Surf. Coat. Technol., 2005, 200, p 2317-2331.

72. M. Fukumoto, E. Nishioka, and T. Matsubara, Effect of Interface Wetting on Flattening of Freely Fallen Metal Droplet onto Flat Substrate Surface, J. Therm. Spray Technol., 2002, 11(1), p 69-74.

73. M. Qu, Y. Wu, V. Srnivasan, and A. Gouldstone, Observations of Nanoporous Foam Arising from Impact and Rapid Solidification of Molten Ni Droplets, Appl. Phys. Lett., 2007, 90, p 254101.

74. K. Yang, M. Fukumoto, T. Yasui, and M. Yamada, Study of Substrate Preheating on Flattening Behavior of ThermalSprayed Copper Particles, J. Therm. Spray Technol., 2010, 19, p 1195-1205.

75. S. Brossard, P.R. Munroe, A. Tran, and M.M. Hyland, Study of the Splat-Substrate Interface for a NiCr Coating Plasma Sprayed onto Polished Aluminum and Stainless Steel Substrates, J. Therm. Spray Technol., 2010, 19, p 24-30.

76. S. Chandra and P. Fauchais, Formation of Solid Splats During Thermal Spray Deposition, J. Therm. Spray Technol., 2009, 18, p 148-180.

77. S.-W. Yao, J.-J. Tian, G.-J. Yang, C.-X. Li, X.-T. Luo, and C.-J. $\mathrm{Li}$, Understanding the Formation of the Limited Interlamellar Bonding in Thermal Spray Ceramic Coatings Based on the Intrinsic Bonding Temperature Concept, J. Therm. Spray Technol., 2016, 25(8), p 1617-1630.

78. A. Denoirjean, A. Grimaud, P. Fauchais, P. Tristant, C. Tixier, and J. Desmaison, Splat formation, first step for multitechnique deposition of plasma spraying and microwave plasma enhanced CVD, Thermal Spray: Meeting in Challenges of the 21st Century. C. Coddet Ed., ASM International, Materials Park, OH, 1998, p 1369-1374

79. S. Valette, A. Denoirjean, and P. Lefort, Plasma Sprayed Steel: Adhesion of an Alumina Film via a Wustite Interlayer, Surf. Coat. Technol., 2008, 202, p 2603-2611.

80. S. Valette, R. Bernardie, J. Absi, and P. Lefort, Elaboration and Characterisation of Plasma Sprayed Alumina Coatings on Nickel with Nickel Oxide Interlayer, Surf. Coat. Technol., 2021, 416, p 127-215.

81. K. Murakami, N. Takuno, T. Okamoto, H. Matsumoto, and T. Miyamoto, Structural changes of mechanical properties of thermal sprayed $\mathrm{Al}-\mathrm{Si}$ and $\mathrm{Ni}-20 \mathrm{wt} \% \mathrm{Cr}$ alloys. In: Thermal Spray: International Advances in Coatings Technology (Proc. International Thermal Spray Conference), Orlando Florida, USA, (ASM International, Materials Park, 1992), p. 387-392

82. D. Steffens, M. Dvorak, and K. Nassenstein, Mechanical properties of vacuum-plasma sprayed titanium and titanium alloys. In: Thermal Spray: International Advances in Coatings Technology (Proc. International Thermal Spray Conference), Orlando Florida, USA, (ASM International, Materials Park, 1992), p. 369-374.

83. T. Nguyentat, K.T. Dommer, and K.T. Bowen, Metallurgical evaluation of plasma sprayed structural materials for rocket engines. In: Thermal Spray: International Advances in Coatings Technology (Proc. International Thermal Spray Conference), Orlando Florida, USA, (ASM International, Materials Park, 1992), p. 321-325.

84. S.J. Tan, D.S. Li, Q.H. Qin, H.B. Liu, X.J. Liao, and L. Jiang, Microstructure and Mechanical Properties of 80Ni20Cr Alloy
Manufactured by Laser 3D Printing Technology, Chin. J. Nonferrous Met., 2017, 27, p 1572-1579. (in Chinese)

85. M. Bitzer, N. Rauhut, G. Mauer, M. Bram, R. Vassen, H.-P. Buchkremer, D. Stover, and M. Pohl, Cavitation-Resistant NiTi Coatings Produced by Low-Pressure Plasma Spraying (LPPS), Wear, 2015, 328-329, p 369-377.

86. G. Mauer, R. Vassen, and D. Stover, Controlling the Oxygen Contents in Vacuum Plasma Sprayed Metal Alloy Coatings, Surf. Coat. Technol., 2007, 201, p 4796-4799.

87. S. Deshpande, S. Sampath, and H. Zhang, Mechanisms of Oxidation and its Role in Microstructural Evolution of Metallic Thermal Spray Coatings - Case study for Ni-Al", Surf. Coat. Technol., 2006, 200, p 5395-5406. https://doi.org/10.1016/j. surfcoat.2005.07.072

88. A. Valarezo and S. Sampath, An Integrated Assessment of Process-Microstructure-Property Relationships for ThermalSprayed NiCr Coating, J. Therm. Spray Technol., 2011, 20(6), p 1244-1258.

89. R.T. Allsop, T.J. Pitt, and J.V. Hardy, The Adhesion of Sprayed Molybdenum, Metall, 1961, 63, p 125-131.

90. F.N. Longo, Metallurgy of Flame Sprayed Nickel Aluminide Coatings, Weld. J., 1966, 45(2), p 66s-69s.

91. S. Kitahara, A Study of the Bonding Mechanism of Sprayed Coatings, J. Vac. Sci. Technol., 1974, 11(4), p 747-753.

92. J.M. Houben and G.G.V. Liempd, Metallurgical interactions of Mo and steel during plasma spraying. In: Proceedings of 10th International Thermal Spray Conference, May 4-7, 1983, (German Welding Institute, Essen, Germany, 1983), p. 66-71.

93. C.-J. Li, C.-X. Li, G.-J. Yang, and Y.-Y. Wang, Examination of Substrate Surface Melting-Induced Splashing during Splat Formation in Plasma Spraying, J. Therm Spray Technol., 2006, 15(4), p 717-724. https://doi.org/10.1361/105996306X146947

94. S. Dallaire, Influence of Temperature on the Bonding Mechanism of Plasma-Sprayed Coatings, Thin Solid Films, 1982, 95(3), p 237-244.

95. L. Li, X.X. Wang, G. Wei, A. Vaidya, H. Zhang, and S. Sampath, Substrate Melting During Thermal Spray Splat Quenching, Thin Solid Films, 2004, 468, p 113-119. https://doi.org/10.1016/ j.tsf.2004.05.073

96. S. Brossard, P.R. Munroe, A.T.T. Tran, and M.M. Hyland, Study of the Microstructure of NiCr Splats Plasma Sprayed on to Stainless Steel Substrates by TEM, Surf. Coat. Technol., 2010, 204, p 1608-1615.

97. J.-J. Tian, S.-W. Yao, X.-T. Luo, C.-X. Li, and C.-J. Li, An Effective Approach for Creating Metallurgical Self-Bonding in Plasma-Spraying of NiCr-Mo Coating by Designing Shell-CoreStructured Powders", ACTA Mater., 2016, 110, p 19-30. https:// doi.org/10.1016/j.actamat.2016.03.020

98. H. Rashid, X.-Y. Dong, J. Wang, X.-J. Liao, Y.-K. Wei, X.-T. Luo, and C.-J. Li, Plasma-Sprayed Al Alloy Coating with Enhanced Lamellar Bonding Through Novel Self-Bonding Strategy, JOM, 2020, 72, p 4604-4612. https://doi.org/10.1007/ s11837-020-04394-z

99. R.S.C. Paredes, S.C. Amico, and A.S.C.M. d'Oliveira, The Effect of Roughness and Preheating of the Substrate on the Morphology of Aluminium Coatings Deposited by Thermal Spraying, Surf. Coat. Technol., 2006, 200, p 3049-3055.

100. E. Pfender, Particle Behavior in Thermal Plasmas, Plasma Chem. Plasma Process., 1989, 9(1), p 167S-194S.

101. Y.P. Wan, J.R. Fincke, S. Sampath, Y. Prasad, and H. Herman, Modeling and Experimental Observation of Evaporation from 
Oxidizing Molybdenum Particles Entrained in a Thermal Plasma Jet, Int. J. Heat Mass Transf., 2002, 45, p 1007-1015.

102. J.-J. Tian, S.-W. Yao, S.-L. Li, and C.-J. Li, Effect of the ShellCore-Structured Particle Design on the Heating Characteristic of Nickel-Based Alloy Particle during Plasma Spraying, Surf. Coat. Technol., 2018, 335, p 52-61. https://doi.org/10.1016/j.surfcoat. 2017.12.019

103. A. Kubo, S. Nagakura, H. Iguchi, and H. Ezawa Eds., Dictionary of Physics and Chemistry, 4th ed. Iwatani Shyoten, Tokyo, 1987, p 364

104. X.-J. Liao, L. Zhang, X.-Y. Dong, X. Chen, X.-T. Luo, C.-X. Li, and C.-J. Li, Self-Bonding Effect Development for Plasma Spraying of Stainless Steel Coating Through Using Mo-Clad Stainless Steel Powders, JOM, 2020, 72, p 4613-4623.

105. C.-J. Li and G.-J. Yang, Akira Ohmori, Relationship between Particle Erosion and Lamellar Microstructure for Plasma Sprayed Alumina Coatings, Wear, 2006, 260, p 1166-2117.

106. P.A. Engel, Impact Wear of Materials, Elsevier Scientific Publishing Company, Amsterdam, 1976, p 104-128

107. K. Haugen, O. Kvernvold, A. Ronold, and S. Sandberg, Sand Erosion of Wear Resistant Materials: Erosion in Chole Valves, Wear, 1995, 186-187, p 179-188.

108. B.Q. Wang, Erosion-Corrosion of Coatings by Biomass-Fired Boiler Fly Ash, Wear, 1995, 188, p 40-48.

109. H.M. Clark, H.M. Hawthorne, and Y. Xie, Wear Rate and Specific Energies of Some Ceramic, Cermet and Metallic Coatings Determined in the Coriolis Erosion Tester, Wear, 1999, 233-235, p 319-327.

110. J.-J. Tian, X.-T. Luo, J. Wang, and C.-J. Li, Mechanical Performance of Plasma-Sprayed Bulk-Like NiCrMo Coating with a Novel Shell-Core-Structured NiCr-Mo Particle, Surf. Coat. Technol., 2018, 353, p 179-189. https://doi.org/10.1016/j.surf coat.2018.08.082

111. C.-J. Li and W.-Y. Li, Effect of Sprayed Powder Particle Size on the Oxidation Behavior of MCrAlY Materials during HVOF Deposition, Surf. Coat. Technol., 2003, 162, p 21-41.

112. T. Fukushima and S. Kuroda, Oxidation of HVOF sprayed alloy coatings and its control by a gas shroud, Thermal Spray 2001: New Surfaces for a New Millennium. C. Berndt, K.A. Khor, E.F. Lugscheider Ed., ASM International, Materials Park, Netherland p, 2001, p 527-532

113. A.A. Syed, A. Denoirjean, P. Fauchais, and J.C. Labbe, On the oxidation of stainless steel particles in the plasma jet, Surf. Coat. Technol., 2006, 200, p 4368-4382.

114. A.A. Syed, A. Denoirjean, P. Denoirjean, J.C. Labbe, and P. Fauchais, In-Flight Oxidation of Stainless Steel Particles in Plasma Spraying, J. Therm. Spray Technol., 2005, 14, p 117124.

115. Kuroda and S. Kitahara, Effects of spray conditions on the pore structure and quenching stress in plasma sprayed coatings. In: A. Ohmori (Ed.), Proceedings of International Thermal Spray Conference, Kobe, Japan (High Temperature Society of Japan, 1995) p. 489-494.

116. G. Espie, P. Fauchais, J.C. Labbe, A. Vardelle, and B. Hannoyer, Oxidation of iron particles during APS effect of the process on formed oxide wetting of droplets on ceramic substrate, Thermal Spray New Surfaces for a New Millennium. C.C. Berndt, K.A. Khor, E.F. Lugscheifer Ed., ASM International Materials Park, USA, 2001, p 821-827

117. C.M. Hackett and G.S. Settles, Turbulent mixing of the HVOF thermal spray and coating oxidation, Thermal Spray Industrial
Applications. C.C. Berndt, S. Sampath Ed., ASM International Materials Park, USA, 1994, p 307-312

118. S. Boire-Lavigne, C. Moreau, and R.G. Saint-Jacques, The Relationship between the Microstructure and Thermal Diffusivity of Plasma-Sprayed Tungsten Coatings, J. Therm. Spray Technol., 1995, 4, p 261-267.

119. J. Matejicek, P. Chraska, and J. Linke, Thermal Spray Coatings for Fusion Applications-Review, J. Therm. Spray Technol., 2005, 16, p 64-83.

120. C. Falia and C. Junling, Property Comparison of Vacuum and Air Plasma Sprayed Tungsten Coatings, J. Alloys Comp., 2021, 861, p 158422.

121. F. Wanga, G.-N. Luo, J. Huange, and Y. Liu, Properties Improvement of Atmospheric Plasma Sprayed Tungsten Coating by Annealing, Surf. Coat. Technol., 2019, 358, p 276-281.

122. S. Sampath, X. Jian, A. Kulkarni, J. Matejicek, D.L. Gilmore, and R.A. Neiser, Development of Process Maps for Plasma Spray: Case Study for Molybdenum, Mater. Sci. Eng. A, 2003, A348, p 54-66.

123. M. Shamsuddin and H.Y. Sohn, Constitutive Topics in Physical Chemistry of High-Temperature Nonferrous Metallurgy: A Review - Part 2. Reduction and Refining, JOM, 2019, 71(9), p 3266-3276.

124. H. Sun, X.Y. Dong, Y. Ren, X.T. Luo, C.X. Li, M. Mahrukh, and C.-J. Li, Influences of Spray Parameters and Powder Composition on the Coating Composition, Microstructure and Properties During Atmospheric Plasma Spraying of $\mathrm{NiCrCuB}$, Therm. Spray Technol., 2021, 13(1), p 1-12. (in Chinese)

125. Y. Ren, X.Y. Dong, H. Sun, X.T. Luo, C.X. Li, M. Mahrukh, and C.-J. Li (2021) Oxide Cleaning Effect of In-flight CuNi Droplet during Atmospheric Plasma Spraying by B addition and Its Influence on the Coating Composition and Structure. Acta Metall. Sin., 2022, 58(2), p 206-214. (in Chinese). https://doi. org/10.11900/0412.1961.2021.00167

126. Y. Zhang, D.E. Mack, M.O. Jarligo, X. Cao, R. Vassen, and D. Stover, Partial Evaporation of Strontium Zirconate During Atmospheric Plasma Spraying, J. Therm. Spray Technol., 2009, 18(4), p 694-701.

127. G. Mauer, D. Sebold, R. Vassen, and D. Stover, Improving Atmospheric Plasma Spraying of Zirconate Thermal Barrier Coatings Based on Particle Diagnostics, J. Therm. Spray Technol., 2012, 21(3-4), p 363-371.

128. S.L. Zhang, T. Liu, C.-J. Li, S.W. Yao, C.X. Li, G.J. Yang, and M.L. Liu, Atmospheric Plasma-Sprayed $\mathrm{La}_{0.8} \mathrm{~S}_{\mathrm{r} 0.2} \mathrm{Ga}_{0.8} \mathrm{Mg}_{0.2} \mathrm{O}_{3}$ Electrolyte Membranes for Intermediate-Temperature Solid Oxide Fuel Cells, J. Mater. Chem., 2015, A3, p 7535-7553.

129. X. Chen, S.L. Zhang, C.X. Li, and C.-J. Li, Optimization of Plasma-Sprayed Lanthanum Chromite Interconnector Through Powder Design and Critical Process Parameters Control, J. Therm. Spray Technol., 2020, 29, p 212-222. https://doi.org/10. 1007/s11666-019-00960-3

130. X. Chen, C.C. Kou, X.J. Liao, C.X. Li, G.J. Yang, K. Huang, and C.-J. Li, Plasma-Sprayed Lanthanum-Doped Strontium Titanate as an Interconnect for Solid Oxide Fuel Cells: Effects of Powder Size and Process Conditions, J. Alloy Compd., 2021, 876, p 160212.

131. L.-S. Wang, S.-L. Zhang, T. Liu, C.-J. Li, C.-X. Li, and G.-J. Yang, Dominant Effect of Particle Size on the $\mathrm{CeO}_{2}$ Preferential Evaporation During Plasma Spraying of $\mathrm{La}_{2} \mathrm{Ce}_{2} \mathrm{O}_{7}$, J. Eup. Ceram. Soc., 2017, 37, p 1577-1585. 
132. H. Zhang, A. Vardelle, and N.J. Themelis, In-flight Oxidation and Evaporation of Plasma-Sprayed Iron Particles, High Temp. Mater. Process., 2003, 7, p 277-298.

133. L. Zhang, D. Wang, X.-J. Liao, X.-T. Luo, and C.-J. Li, The influence of diamond addition to Ni-Al powder on oxidation behavior of NiAl during plasma spraying for high performance Ni-Al intermetallic coating. In: Proceedings of 2021 ITSC, (ASM International, Materials Park, USA, 2021)

134. X.-J. Li Zhang, S.-L. Liao, X.-T. Zhang, and C.-J. Li, Effect of Powder Particle Size and Spray Parameters on the Ni/Al Reaction During Plasma Spraying of Ni-Al Composite Powders,
J. Therm. Spray Technol., 2021, 30(1-2), p 181-195. https://doi. org/10.1007/s11666-020-01150-2

135. A. Vardelle, M. Vardelle, H. Zhang, N.J. Themelis, and K. Gross, Volatilization of Metal Powders in Plasma Sprays, $J$. Therm. Spray Technol., 2002, 11, p 244-325.

Publisher's Note Springer Nature remains neutral with regard to jurisdictional claims in published maps and institutional affiliations. 